\title{
Developing Flow Pattern Maps for Accelerated Two-Phase Capillary Flows
}

\author{
Luca Pietrasanta*1, Mauro Mameli², Daniele Mangini ${ }^{3}$, Anastasios Georgoulas ${ }^{1}$, Nicholas Michè ${ }^{1}$, Sauro \\ Filippeschi $^{2}$, Marco Marengo ${ }^{1}$ \\ ${ }^{1}$ School of Computing, Engineering and Mathematics, University of Brighton, Lewes Rd, Brighton BN2 4AT, UK. \\ ${ }^{2}$ University of Pisa, Largo Lucio Lazzarino 2, 56122 Pisa, Italy. \\ ${ }^{3}$ HE Space Operations BV for ESA, NL-2200AG Noordwijk, The Netherlands. \\ *corresponding author: L.Pietrasanta2@brighton.ac.uk
}

\begin{abstract}
The prediction of flow pattern transitions is extremely important to understand the coupling of thermal and fluid dynamic phenomena in two phase systems and it contributes to the optimum design of heat exchangers. Two phase flow regimes have been extensively studied under controlled mass flow rate and velocity. On the other hand, less effort has been spent in the literature on the cases where the flow motion is purely thermally induced and consequently the mass flow rate or the velocity of the phases are not known a priori. In the present work, flow pattern transitions and bubble break-up and coalescence events have been investigated in a passive two phase wickless capillary loop, where the mass flow rate is intrinsically not controllable. Modified Froude, Weber and Bond numbers have been introduced, considering the actual acceleration of the fluid and the length of the bubble as merit parameters for the transitions. The proposed nondimensional investigation was developed by analysing experimental data obtained with ethanol and FC-72, as working fluids, different heat input levels (from 9 to $24 \mathrm{~W}$ ) as well as three different gravity levels (through a parabolic flight campaign). A new empirical diabatic flow pattern map for accelerated two-phase capillary flows is presented, together with quantitative criteria for the calculation of the flow regime transitions, defining the physic limits for the bubble coalescence and break-up. This kind of new regime maps will be useful to the further development of comprehensive designing tools for passive two-phase wickless heat transfer devices.
\end{abstract}

Keywords: Pulsating Slug Flow, Flow Pattern Maps, Visual Investigation, Bubble Length;

\section{INTRODUCTION}

The constant demand for innovation in heat transfer solutions for compact and more powerful electronics is driving the research towards new technologies able to dissipate more power in reduced dimensions. Two-phase thermal management systems can achieve an enhancement in heat transfer coefficient by orders of magnitude compared to single phase systems in heat transfer coefficient. The flow pattern in a two-phase fluid flow has a critical role on heat transfer coefficients and pressure drop. The physics governing the pressure drop and the heat transfer in a two-phase flow are intrinsically linked to the local distribution of the liquid and vapor phases [1]. Flow pattern transitions, as a form of two-phase instability [2], have been widely investigated to predict the range of functioning parameters for safe operations or to pursue maximum performances in heat exchangers.

Flow pattern maps have been experimentally and theoretically determined for many industrial applications of two-phase flows, ranging from macro-scale (i.e. oil and gas extraction and transport) to micro-scale (micro heat exchangers). Extending the range of application of two-phase macroscale flow pattern maps to micro-scale twophase flows leads to unrealistic outputs, given the different mutual relevance of forces involved: the relative importance of surface tension, inertia, buoyancy and viscosity. A simple classification based on the channel diameter, has been proposed by Cheng and $\mathrm{Wu}$ [3], with a distinction based on the Bond number which takes into account the differences between working fluids, but no inertial effects: macro-channels (Bo $>3)$, meso-channels $(0.005<\mathrm{Bo}<3)$ and micro channels $(\mathrm{Bo}<0.05)$. For practical uses, the $\mathrm{Bo}<4$ threshold between confined and 

so-called static criterion of confinement is obtained:

$$
d_{\text {crit }}(B o) \leq 2 \sqrt{\sigma B o_{\text {crit }} / g\left(\rho_{l}-\rho_{v}\right)}
$$

unconfined flow proposed by Kew and Cornwell [4], is still widely adopted. By making the diameter explicit, the

An attempt of including inertial effects in the definition of a threshold between confined and unconfined flow, has been made by Harirchian \& Garimella [5]. The parameter $\mathrm{Bo}^{0.5} \mathrm{Re}$ has been named convective confinement number and a transition limit $\mathrm{Bo}^{0.5} \mathrm{Re}=160$, has been obtained as a curve fitting of the transition points; rearranging the empirical limit in order to make explicit a critical value of the internal diameter, as shown in (1)

$$
d_{c r i t}(G a) \leq \sqrt{160 \mu_{l} / \rho_{l} v_{l} \sqrt{\sigma / g\left(\rho_{l}-\rho_{v}\right)}}
$$

where $\mathrm{Ga}=\mathrm{Bo}^{0.5} \mathrm{Re}$ is known as the Garimella number [6]. This empirical transition criterion is independent from the heat flux, but still requires modified empirical correlations or regime-based models to more precisely account for the microscale effects.

The effort in predicting flow pattern transitions has produced a variety of flow pattern maps where the transitions within regimes are observed either in flow pattern databases resulting from experimental campaigns (Empirical Maps) or predicted from physical models (Theoretical Maps). The boundaries between different flow patterns are then plotted against a system of coordinates involving at least two flow parameters. Table 1 summarises some of the most relevant examples of flow pattern maps developed for millimetric and micrometric channels, with the corresponding system of coordinates. Usually, the system of coordinates chosen can includes phase velocities or fluxes (i.e. superficial gas velocity vs. liquid velocity), resulting in a map that is valid exclusively for specific set of conditions or fluids tested. Some other coordinate systems include quantities referring to the two-phase flow (i.e. total velocity, void fraction, vapour quality) and they have been proven useful to accurately describe only selected flow patterns. For a map to be considered universal, the forces related to each physical phenomenon (i.e. Re, We, kinetic energy) need to be taken into account. Currently, no universal flow pattern map extendable to different geometries and fluids, which includes all parameters influencing vapor-liquid flows in micro- and minichannels, is available as remarked during the years by Shao, Gavriilidis \& Angeli [7], Harirchian \& Garimella [5] and more recently by Thome et al. [8].

Flow regime prediction tools developed so far in the literature cannot cope with the design of two-phase, passive, heat transfer devices where the flow motion is thermally induced and also subjected to continuous variation of the acceleration magnitude and direction. The need for developing specific flow pattern maps extendable to the cases where the mass flow rate is not known like in Pulsating Heat Pipes and in Thermosyphons, constitutes the motivation of the present investigation. Understanding the conditions that causes the occurrence of a slug-plug flow is necessary in both devices for opposite reasons. During the operation of a Pulsating Heat Pipe [9], a train of elongated bubbles separated by liquid slugs is required to allow an overall circulation of the working fluid and consequently obtain a passive heat transfer from the evaporator to the condenser exploiting both sensible and latent contributions. The thermally induced fluid flow is subjected to continuous variations of acceleration magnitude and direction (reverse flow), heat transfer rate, pressure drop and bubble growing phenomena that occur alongside with variation of the liquid film thickness and presence of local dry-outs. In Thermosyphons, a Taylor-like bubble is generated when nucleation phenomena cause a quick grow of the size of the bubble leading to a confinement condition that traps some liquid above the pool; this causes an unwanted oscillating behaviour that reduces the thermal performance and affects the long-term reliability. Probably one of the most relevant work in the literature that supports the importance and novelty of this one is Smith et al. [10], which also highlighted the limited research in the description of the flow regime in small dimension two-phase heat transfer devices. Albeit for a reflux thermosyphon (8mm I.D.), they did in fact develop the first flow detailed regime map and highlighted how important is confinement, quantifying the level of confinement of growing bubbles with the Confinement number (Co), but not explicitly considering inertial parameters grouped in non-dimensional numbers. Moreover, Smith et al. [11] investigated the effect of the heat flux on the confinement conditions analysing the vapour generation rate in the devices and then to the convective heat transfer. The available tools to predict the flow pattern in a capillary two-phase flow have been generally developed under unidirectional steady state flow with constant mass velocity. 
Moreover, most of the studies are based on observations in adiabatic flow conditions produced by mixing known rates of vapor and liquid at the inlet of the test section. A flow pattern map able to represent the flow conditions of a PHP could be used to implement the existence limits for the slug-plug flow in lumped parameter models. For instance, several codes developed in the literature [12] [13] [14], that are also partially validated, assume the slugplug flow as a prescribed starting condition, maintaining it throughout the simulations. When a real system would reach the transition to an annular flow for example, the proposed lumped parameter codes would keep on applying the same equations as for the slug-plug regime, resulting in thermal and hydraulic predictions that are affected by significant bias.

Table 1 Flow pattern map development for milli- and micro-channels.

\begin{tabular}{|c|c|c|c|c|}
\hline Authors & Diameter & Type of flow & Fluid & System of Coordinates \\
\hline $\begin{array}{l}\text { Revellin \& Thome } \\
\text { 2007[15] }\end{array}$ & $\begin{array}{c}\text { Straight Tube } \\
0.509 \mathrm{~mm} \\
0.790 \mathrm{~mm}\end{array}$ & $\begin{array}{l}\text { Horizontal } \\
\text { Diabatic }\end{array}$ & $\begin{array}{l}R-134 a \\
R-245 f a\end{array}$ & $\begin{array}{c}\mathrm{x} \text { : Vapour quality [-] } \\
\mathrm{y}: \text { Mass velocity }\left[\mathrm{kg} / \mathrm{m}^{2} \mathrm{~s}\right]\end{array}$ \\
\hline $\begin{array}{c}\text { Harirchian \& } \\
\text { Garimella 2010[5] }\end{array}$ & $\begin{array}{c}\text { Straight } \\
\text { Rectangular } \\
\text { Dhyd: } \\
96 \mu \mathrm{m} \text { to } 707 \mu \mathrm{m}\end{array}$ & $\begin{array}{l}\text { Horizontal } \\
\text { Diabatic }\end{array}$ & FC-77 & $\begin{array}{l}x: B o \\
y: \operatorname{Re}\end{array}$ \\
\hline $\begin{array}{l}\text { Ong \& Thome } \\
\text { 2011[16] }\end{array}$ & $\begin{array}{l}\text { Straight Tube } \\
1.03 \mathrm{~mm} \\
2.20 \mathrm{~mm} \\
3.04 \mathrm{~mm}\end{array}$ & $\begin{array}{l}\text { Horizontal } \\
\text { Diabatic }\end{array}$ & $\begin{array}{l}R-134 a \\
R-236 f a \\
R-245 f a\end{array}$ & $\begin{array}{c}\mathrm{x}: \text { Vapour quality }[-] \\
\mathrm{y}: \text { Mass velocity }\left[\mathrm{kg} / \mathrm{m}^{2} \mathrm{~s}\right]\end{array}$ \\
\hline Celata et al. 2012[17] & $\begin{array}{l}\text { Straight Tube } \\
0.48 \mathrm{~mm}\end{array}$ & $\begin{array}{l}\text { Horizontal } \\
\text { Diabatic }\end{array}$ & FC-72 & $\begin{array}{c}\mathrm{x}: \text { Vapour quality }[-] \\
\mathrm{y}: \text { Mass velocity }\left[\mathrm{kg} / \mathrm{m}^{2} \mathrm{~s}\right]\end{array}$ \\
\hline Puccetti et al. 2015[18] & $\begin{array}{l}\text { Rectangular micro } \\
\text { T- junction } \\
300 \mu \mathrm{m} \times 256 \mu \mathrm{m}\end{array}$ & $\begin{array}{l}\text { Horizontal } \\
\text { Adiabatic }\end{array}$ & Water-Air & $\begin{array}{l}\mathrm{x}: \text { Vapour superficial } \\
\text { velocity }[\mathrm{m} / \mathrm{s}] \\
\mathrm{y}: \text { Liquid superficial } \\
\text { velocity }[\mathrm{m} / \mathrm{s}]\end{array}$ \\
\hline $\begin{array}{l}\text { Saisorn \& Wongwises } \\
2015[19]\end{array}$ & $\begin{array}{l}\text { Straight Tube } \\
0.53 \mathrm{~mm}\end{array}$ & $\begin{array}{l}\text { Vertical } \\
\text { Adiabatic }\end{array}$ & Water-Air & $\begin{array}{l}\text { x: Vapour superficial } \\
\text { velocity }[\mathrm{m} / \mathrm{s}] \\
\mathrm{y}: \text { Liquid superficial } \\
\text { velocity }[\mathrm{m} / \mathrm{s}]\end{array}$ \\
\hline Smith et al. 2018[10] & $\begin{array}{l}\text { Thermosyphon } \\
\text { 8mm I.D. }\end{array}$ & $\begin{array}{l}\text { Vertical } \\
\text { Diabatic }\end{array}$ & $\begin{array}{c}\text { Water } \\
\text { Ethanol } \\
\text { HFE-7000 }\end{array}$ & $\begin{array}{l}\mathrm{x}: \text { Confinement number } \\
\mathrm{y}: \text { Vapour production } j^{*}{ }_{v}\end{array}$ \\
\hline $\begin{array}{l}\text { Malhotra \& Ghosh } \\
2019 \text { [20] }\end{array}$ & $\begin{array}{c}\text { Rectangular } \\
\text { serpentine } \\
\mathrm{D}_{\text {hyd }}: \\
1.65 \mathrm{~mm} \\
1.00 \mathrm{~mm} \\
0.65 \mathrm{~mm}\end{array}$ & $\begin{array}{c}\text { Horizontal \& } \\
\text { Vertical } \\
\text { Adiabatic }\end{array}$ & Water-Air & $\begin{array}{l}\mathrm{x}: \mathrm{We}_{\mathrm{l}} \\
\mathrm{y}: \mathrm{We}_{\mathrm{v}}\end{array}$ \\
\hline
\end{tabular}

\subsection{Dynamic effects on flow pattern transition}

Depending on the interaction between the gravitational, interfacial, inertial and viscous forces, the two-phase flow in micro-channels can result in different regimes. The velocity field of the two phases can affect the flow pattern in different ways. The gas phase, that usually travels faster than the liquid, contributes in determining the thickness of the liquid film, influencing heat and mass transfer in the channel [21]. When the gas velocity in a slug/plug flow increases in a relatively slow liquid, the void fraction tends to increase due to coalescence of adjacent bubbles, causing the system to evolve in an annular flow [7].

The velocity of the fluid flow is involved in defining whether inertia plays a dominant role over surface tension. High velocities cause flow inertia to dominate any surface tension or gravity effect, producing similar flow patterns for all the gravity levels [22].

Under steady state and adiabatic conditions, no considerable changes in the dynamic forces affect the fluid flow; 
the only body force acting on the fluid is gravity. Rouhani and Sohal [23] reviewed the effects of acceleration on flow regime transitions, identifying its crucial role and a lack of experimental studies. Additional forces, linked to pressure variation due to boiling and condensation phenomena, result in acceleration or deceleration of the flow, having a critical effect on the flow pattern transition. An effect of the acceleration and deceleration of the fluid on the liquid film thickness has been identified, with the initial velocity also playing a role [24]. In the case of an oscillating flow [25], as the frequency and amplitude of the oscillation are increased, the liquid film thickness deviates from that in the steady condition and becomes thinner or thicker under flow acceleration or deceleration, respectively.

The difference in density between the two phases and the flow conditions (velocity and acceleration), are responsible for the generation and propagation of disturbances at the vicinity of the liquid/vapour interface. In a confined flow, disturbances generated on the advancing interface are transported down the side of the bubble into the liquid film due to the different velocities of the two phases. These disturbances, possibly due to a KelvinHelmholtz type mechanism, can result in ring waves affecting high void fraction elongated bubbles [26].

\subsection{Effect of vapour bubble length on flow pattern transition}

Among the parameters affecting the two-phase flow pattern, acting especially on the coalescence of bubbles and then on the resultant void fraction, the literature available includes the length of the bubble as one of the most relevant. Thome et al. [8] proposed a mechanistic multiscale mapping of two-phase flow pattern in microchannels illustrating the strong dependency of heat transfer on bubble frequency, lengths of the bubbles and liquid slugs, and the liquid film thickness $\delta$. Wang et al. [27] described how bubble break up in microfluidics junctions is affected by the length of the bubble, the width of the microchannel, the phase velocities and the capillary number. By analysing the effects of these factors on the dynamical evolution of gas-liquid interface, the authors formulate an expression for describing the bubble deformation and eventually break-up, that includes the bubble length. A parametric numerical study presented by Pietrasanta et al. [28], conducted on a two-phase flow in a circular millimetric channel under instantaneous pressure drops, suggested that both the bubble length as well as the liquid film thickness have a significant effect on the liquid film dynamics and on the break-up mechanism. The elongation of the bubble in adiabatic conditions exposes the vapour bubble to the propagation of ridges or ring waves, that penetrate in the body of the bubble, locally narrowing the cross section and facilitating the break-up. The breakup takes place when the local balance of forces due to the surface tension (calculated with the radius of the ridge) overcomes the vapour pressure.

To the best of our knowledge, the role of the vapour plug length has not yet been correlated to velocity and acceleration of the fluid in the context of PHPs.

\section{Experimental set-up and data reduction procedure}

In the present investigation, a two-phase flow characterised by varying dominant flow patterns, has been established in a millimetric cross-section loop. The experiments are performed for 2 different working fluids (Ethanol and FC72) for a wide range of experimental conditions including heat power input and gravity level. Three gravity levels are achievable on board of an aircraft performing parabolic ballistic manoeuvre [29].

\subsection{Test cell}

The test cell adopted in this work is a simplified geometry of a PHP originally described by Mangini et al. [30], able to preserve the peculiar functioning characteristic of the PHP while reducing its complexity and the number of involved parameters. It consists of a closed loop pipe, with four 90 degrees turns, designed to facilitate high speed imaging and high-accuracy, high-frequency pressure investigation, coupled with temperature measurements. The main components of the system are shown in Figure 1. The evaporator and the condenser are made of copper tubes (I.D./O.D. $2 \mathrm{~mm} / 4 \mathrm{~mm}$ ) and are connected to two sapphire tubes (110 $\mathrm{mm}$ axial length, same I.D./O.D. of 
the copper tubes) by means of brass joints specially designed to preserve the flow path geometry and host the pressure transducers ( 1 bar absolute, accuracy $0.05 \% \mathrm{FSO}, 100 \mathrm{~Hz}$ acq. freq.). Twelve T-type thermocouples $(10 \mathrm{~Hz}$ acq. freq.) that monitor the external wall temperature are placed both in the heated and in the cooled section. The high-speed camera (Ximea ${ }^{\circledR}$ USB3 XIQ-093, resolution 1280x1024 pixel) records images of both the channels at $100 \mathrm{fps}$, with synchronized pressure and temperature measurements. Three electrical heaters (Thermocoax ${ }^{\circledR}$ Single core $1 \mathrm{Nc} \mathrm{Ac}$ ) are coiled around the evaporator in three sections, providing a nominal wall-to-fluid heat flux of 6.5 $\mathrm{W} / \mathrm{cm}^{2}$ at $10 \mathrm{~W}$. The heat supplied is calculated using the recorded values of voltage (V) and current (I). The heaters are controlled independently, to vary the heating distribution along the heated zone. The independent control of the heating elements allows non-symmetrical heating with respect to the gravity field to promote the fluid circulation in a preferential direction. The acquisition system (National Instruments ${ }^{\circledR}$ c-RIO 9047) is controlled by a LabView ${ }^{\circledR}$ software that triggers the acquisition of all the signals and the high-speed camera. Two working fluids, with a volumetric ratio of 0.6 corresponding to $1.45 \mathrm{ml}$, have been tested: Ethanol and FC- 72. The internal diameter has been kept $2 \mathrm{~mm}$ throughout all the experimental campaigns, in order to obtain two completely different behaviours of the fluid at varying gravity level. That means, according to the Bond criterion for critical diameter at $1 \mathrm{~g}$, the device filled with ethanol is always operating under critical diameter conditions while for FC72 is operating in non-critical conditions for $1 \mathrm{~g}$ and Hyper-g (Closed Loop Thermosyphon mode) with a transition to critical in micro-g (PHP mode).

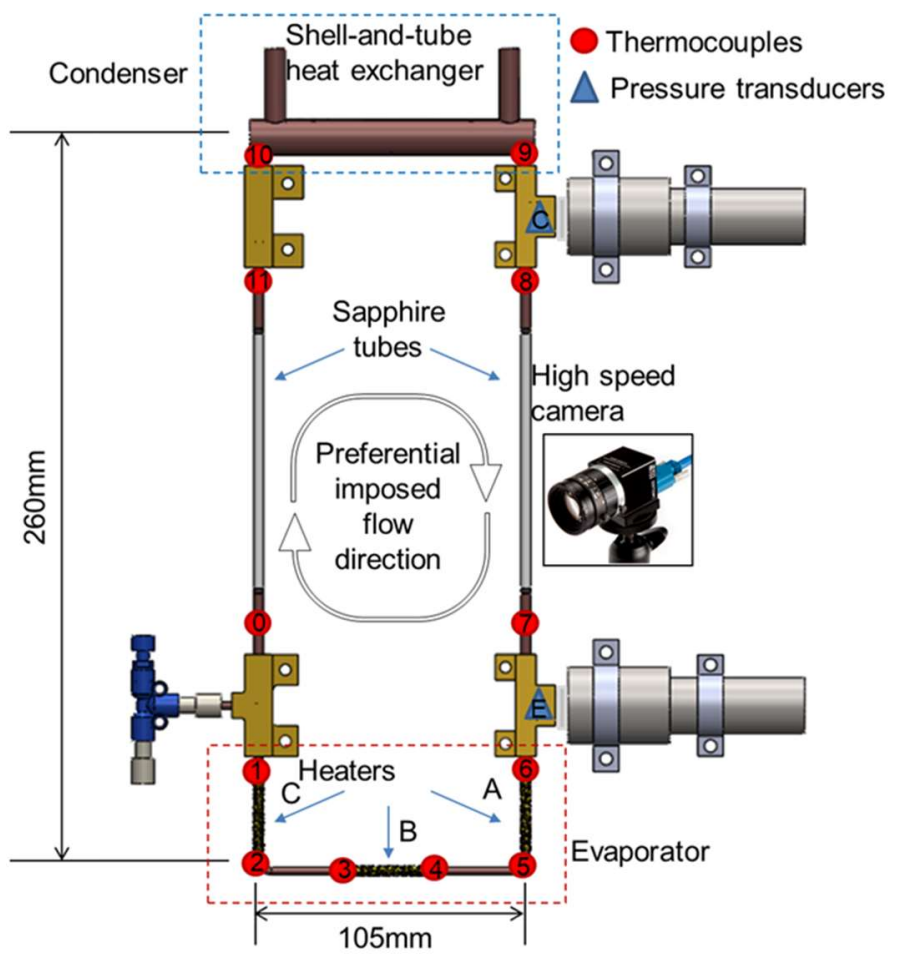

Figure 1 Capillary passive two phase loop with thermocouples and pressure transducers location [31]

Figure 2 shows the static critical diameter over a range of temperature for the two fluids [4]. The effect of the fluid temperature is reflected on the thermo-fluid-dynamic properties of the fluids involved in eq. (2); given the internal diameter of the test cell, operating at different temperatures may cause a transition to or from the confined state. In order to give a more intuitive idea of the confinement conditions relative to the combination working fluidchannel, also the trend of the Confinement number is provided, where Co is defined as:

$$
C o=\frac{1}{d_{i}} \sqrt{\sigma / g\left(\rho_{l}-\rho_{v}\right)}
$$


very small confinement number means that bubbles are very small compared with the channel size and confinement effects are small. As a reference, Figure 3 shows the indication of the confinement number trend with 3 temperature for both working fluids.

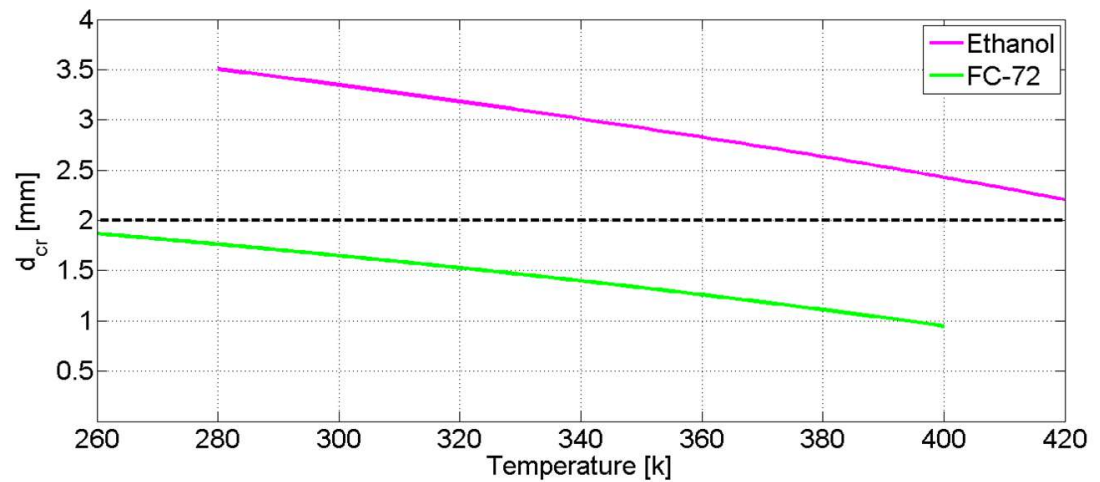

Figure 2: Critical diameters according to the static Bond criterion [4]) for ethanol and FC-72, in the temperature range of operation. Black dashed line refers to the internal diameter of the present work.

From Figure 2 it can also be seen that the effect of the variation of the operating temperature on the thermodynamic properties of the working fluids, does not trigger transitions in the range of interest for both fluids, so any transition should be triggered only by:

- a change in the gravity field;

- a dynamic effect (velocity and acceleration of the phases).

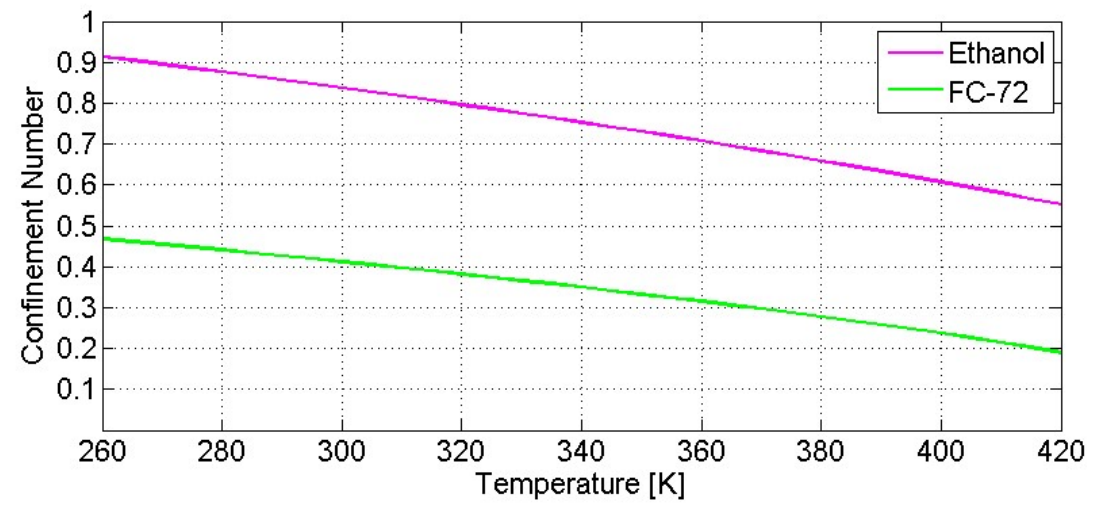

Figure 3: Confinement number for the two combinations of working fluid-channel.

9

\subsection{Experimental procedure}

The device has been tested in vertical position, bottom heated mode (BHM), during two parabolic flight campaigns (ESA PFC $66^{\text {th }} \& 68^{\text {th }}$ ) under different heating configurations. The same experimental matrix has been adopted for both fluids. The flight test procedure, in terms of power input to the evaporator, is reported in Table 2 as well as the detail of the power supplied to the three heaters. These specific heating patterns have been tested onground and proved able to impose a preferential direction to the flow. 
Table 2 Parabolic flight experimental matrix.

\begin{tabular}{l|c|c|c|c}
\hline \multirow{2}{*}{ Parabola N. } & \multirow{2}{*}{ Total Power [W] } & \multicolumn{3}{|c}{ Power allocation [W] } \\
\cline { 3 - 5 } & & Heater A & Heater B & Heater C \\
\hline Parabola 0 & 15 & 0 & 6 & 9 \\
Parabola 1-5 & 9 & 0 & 6 & 3 \\
Parabola 6-10 & 15 & 0 & 6 & 9 \\
Parabola 11 & 15 & 0 & 6 & 9 \\
Parabola 12-15 & 18 & 0 & 6 & 12 \\
Parabola 16 & 18 & 0 & 6 & 12 \\
Parabola 17-20 & 24 & 0 & 9 & 15 \\
Parabola 21 & 18 & 0 & 6 & 12 \\
Parabola 22-25 & 21 & 0 & 9 & 12 \\
Parabola 26 & 15 & 0 & 3 & 12 \\
Parabola 27-30 & 27 & 6 & 9 & 12 \\
\hline
\end{tabular}

\subsection{Fluid velocity and acceleration estimation}

In the present investigation, a high-speed shadowgraph investigation has been performed on both transparent sections. The velocity of the liquid phase is evaluated processing high-speed $(100 \mathrm{~Hz})$ imaging starting from the output of a multiple-position, liquid phase sensitive, Particle Image Velocimetry (PIV)-based method, where the original source code has been developed by Taylor et al. 2010 [32]. The procedure of this investigation is to statistically extract the average displacement of several interfaces in a given interrogation windows followed by the division of the displacement with the known time interval $\Delta t$ between two consecutive frames $(0.01 \mathrm{~s})$. In this case the fluid is not seeded with tracer particles but through the difference in pixel intensity, characteristic of the liquid/vapour interfaces (i.e. the menisci), has been exploited to track the velocity of the bubbles. In order to track a meniscus, each frame is segmented into a grid where $I$ is the number of nodes in the y direction and $J$ the number of nodes in the $X$ direction (Figure 4). The spacing of the nodes along the radial dimension has been fixed to 8 pixels, with a pixel being $33 \mu \mathrm{m}$. The PIV software allocates a value for each velocity component $(X$ and $Y)$ to each node, responding to the variation in pixels intensity characteristic of a liquid/vapour interface.

In PIV, a drastic increase of the error is observed when the particle size is less than one pixel; the shadow of an interface, in this work, is typically 4 pixels in the direction of the flow, reducing pixel-locking risk. In our case, which is an adaptation of a PIV technique to a shadowgraph imaging sequence, we are interested in estimating the maximum error, given by the resolution of the measurement. Given the pixel length lpix $=33 \mu \mathrm{m}$, if we consider \pm _lpix as the method resolution, and the sampling frequency is $f=100 \mathrm{fps}$, the estimation of the maximum error on the velocity measurement is:

$$
e_{v, \max }=2 \cdot l_{\text {pix }} \cdot f=2 \cdot 33 \mu \mathrm{m} \cdot 100 \frac{1}{\mathrm{~s}}=0.0066 \frac{\mathrm{m}}{\mathrm{s}}
$$

Note that the error on the acquisition frequency is considered negligible. This is considered the maximum absolute error due to the estimation of the meniscus position by the PIV software. The velocity values are obtained at 8 radial positions; the average of the resulting values is going to give a more accurate estimation of the real velocity. 


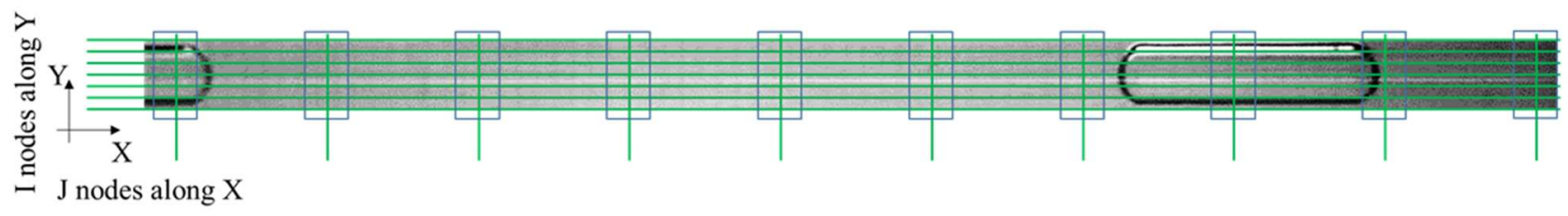

Figure 4 Velocity nodes grid and position of the radial and vertical averaging sections (green grid).

The procedure for extracting the velocity is the following:

1) Radial Averaging: Average of the $I$ nodes excluding the four nodes nearest to the wall (two nearest to the upper wall, two nearest to the lower wall) at every $J$ position;

2) Axial Averaging: The maximum average is chosen since it is considered the most relevant to define the overall motion of the fluid;

3) Time evolution: The averaging procedure described above is repeated for each frame in order to have a trend of the average velocity in a selected interval;

4) Calibration: The estimation method has been calibrated with the velocity obtained from seven imposedvelocity synthetic frame series, in the range of velocity between 0.05 and $0.5 \mathrm{~m} / \mathrm{s}$. The velocities obtained from the PIV-software have been corrected with the calibration curve here obtained

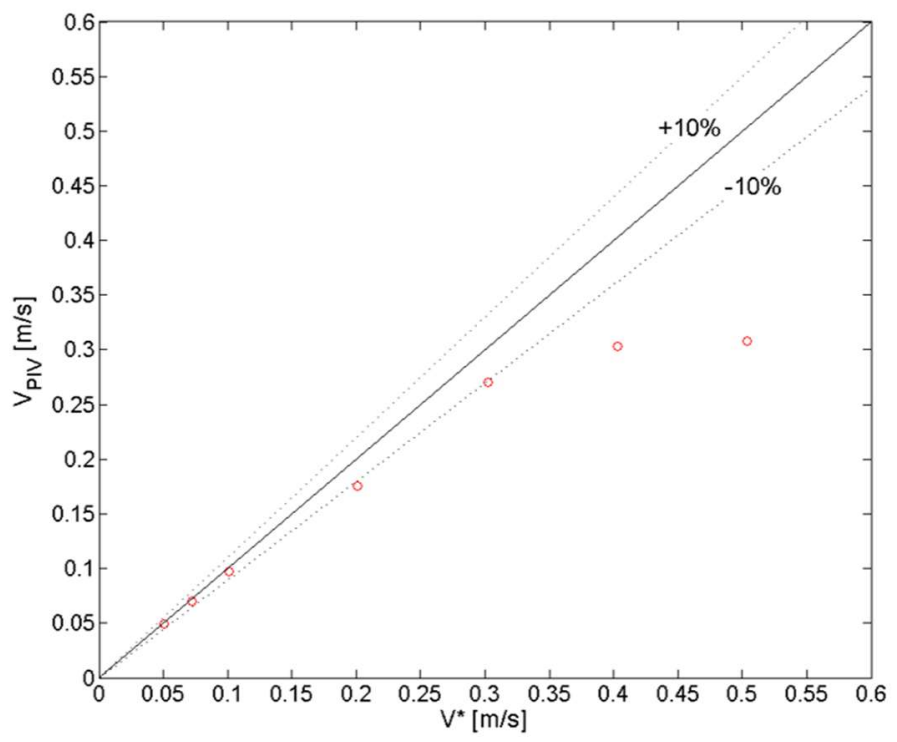

Figure 5 Velocity calibration curve. ( $\left.\mathrm{V}^{*}\right)$ imposed velocity: estimated velocity ( $\left.\mathrm{V}_{\mathrm{PIV}}\right)$.

In the present work the expected maximum velocities are in the range $0.2-0.45 \mathrm{~m} / \mathrm{s}$ making the velocity code applicable in the specific range with known and acceptable accuracy. Test conducted on a single loop pulsating heat pipe by Spinato et al. [33] for power input varying between $30 \mathrm{~W}$ and $65 \mathrm{~W}$, shows a velocity range of 0.07 and $0.15 \mathrm{~m} / \mathrm{s}$, graphically evaluated from a time-strips method at the evaporator. This confirms the applicability of the code in the specific range of velocity values, also from comparison with experimental data from similar geometries.

The estimation of the acceleration of the interfaces is performed with a first order forward finite difference approximation of the term $d v / d t$ :

$$
v^{\prime}(t)=\frac{v(t+h)-v(t)}{h}+O(h)
$$


derivative terms). The maximum error associated with this estimation can be defined as:

$$
e_{a, \max }=2 \cdot e_{v, \max } \cdot f=2 \cdot 0.0066 \frac{\mathrm{m}}{\mathrm{s}} \cdot 100 \frac{1}{\mathrm{~s}}=1.32 \frac{\mathrm{m}}{\mathrm{s}^{2}}
$$

\subsection{Void fraction and Bubble length estimation}

The void fraction is a fundamental quantity in the description and analysis of two-phase flows; in the case of transition from slug to annular flows the void fraction at any point varies dramatically with time, therefore, a continuous record of void fraction is desirable to describe the flow. The volume average void fraction, $\alpha$, in a twophase mixture is defined as the ratio of the volume of gas in the mixture over the total volume available for both phases. Normally, in considering void fraction, the time-average value (taken over a long period of time) is used, but the void fraction is fluctuating with time and instantaneous values are of great interest. To the knowledge of the author, this is the first attempt of estimation of the void fraction in the adiabatic section of a working PHP-like device.

The void fraction has been estimated starting from the high-speed imaging acquired during the $66^{\text {th }}$ and $68^{\text {th }}$ ESA Parabolic Flight campaigns and during the On-Ground campaign. The $100 \mathrm{fps}$ sequences has been processed via a routine developed in the context of the present study, in order to obtain a binarization of the starting images (Figure 6). The main assumption of the code is considering the vapour bubble symmetrical with respect to the channel axis. This approximation has been considered sufficient for the purposes of this work, where not the liquid film thickness nor the interface shape are object of investigation.

For the estimation of $\alpha$, every bubble has been divided in columns spaced 1 pixel each. Along each column belonging to the same bubble, the script count the number of white pixels and calculate the volume of a disk with diameter the number of the white pixels along the column and height 1 pixel.

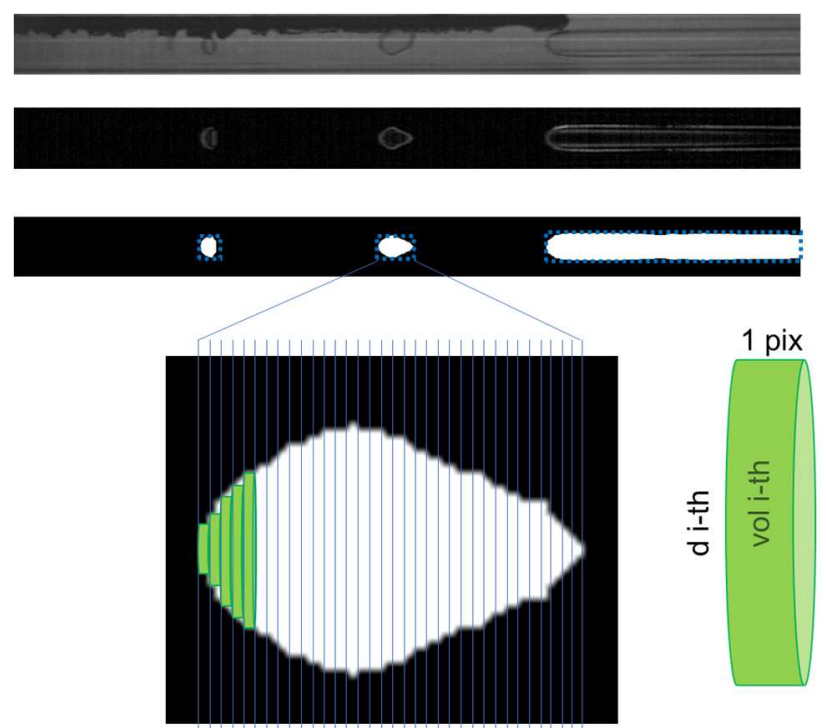

Columns belonging to the bubble

Figure 6 Binarization process of the original frame and successive estimation of a bubble volume as sum of infinitesimal disks

The volume of the i-th bubble $\left(V_{i}\right)$ is then given by the sum of the volume of each disk. The total volume of vapour in each frame is then the sum of the volume of each bubble detected:

$$
V_{t o t}=\sum_{i=1}^{n} V_{i}
$$


via VOF simulation (with known void fraction) with a gaussian noise added. The difference between the actual void fraction and the measured one has been estimated to be less than $2 \%$. With the same code, the length of each

3 bubble in each frame has been estimated.

\section{Results and discussion}

Three different dominant regimes were observed in the visualisation of the direct flow, following the direction condenser to evaporator (down-comer). The other channel (up-header) is constantly showing a clear annular flow pattern (Table 3, frame c) while the down-comer shows transitions between Taylor flow (Table 3, frame a) and semi-annular (Table 3, frame b) or annular (Table 3, frame c) depending on the thermo-dynamic conditions.

Table 3: Dominant flow pattern identified during the functioning of the PHP test-rig

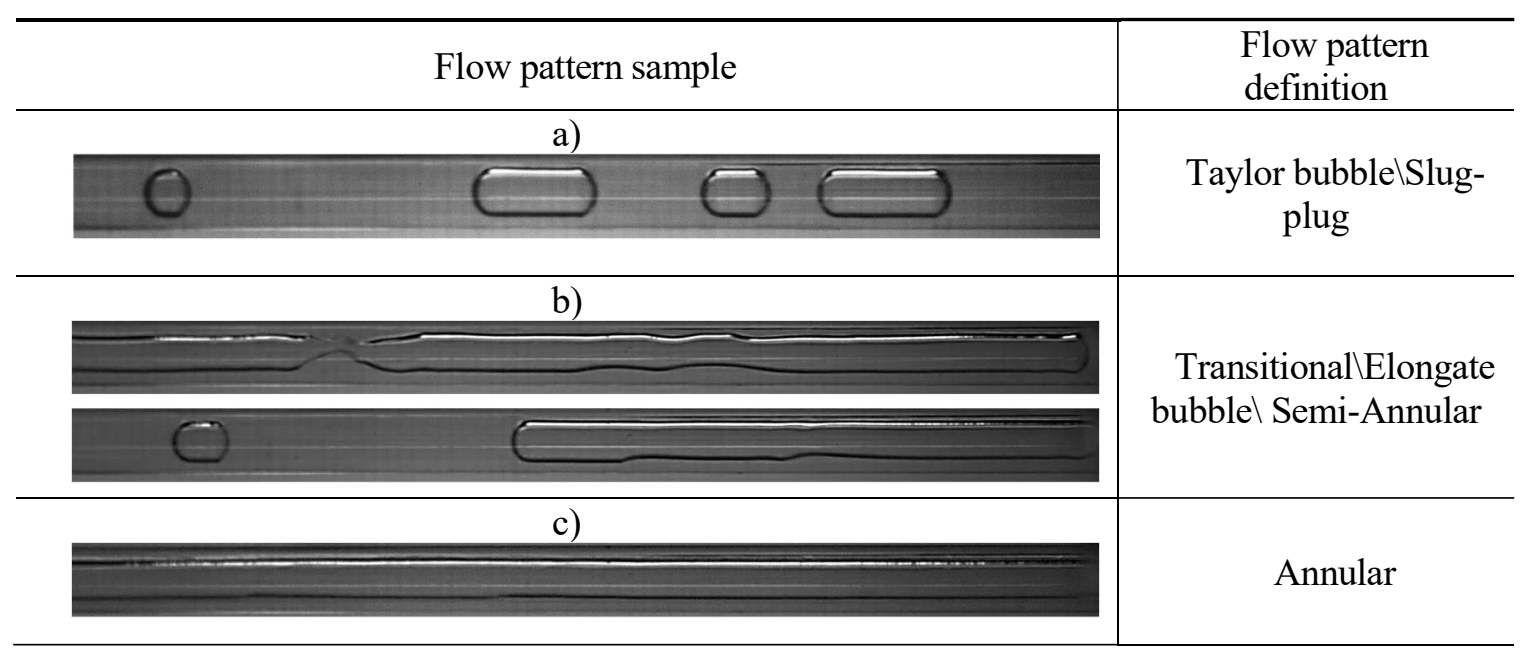

For the identification of the flow pattern, a statistical analysis has been performed at different power input, gravity level and for the two fluids used (Figure 7). This information, combined with the bubble length, made possible the automatic identification process of the 1200 experimental points.
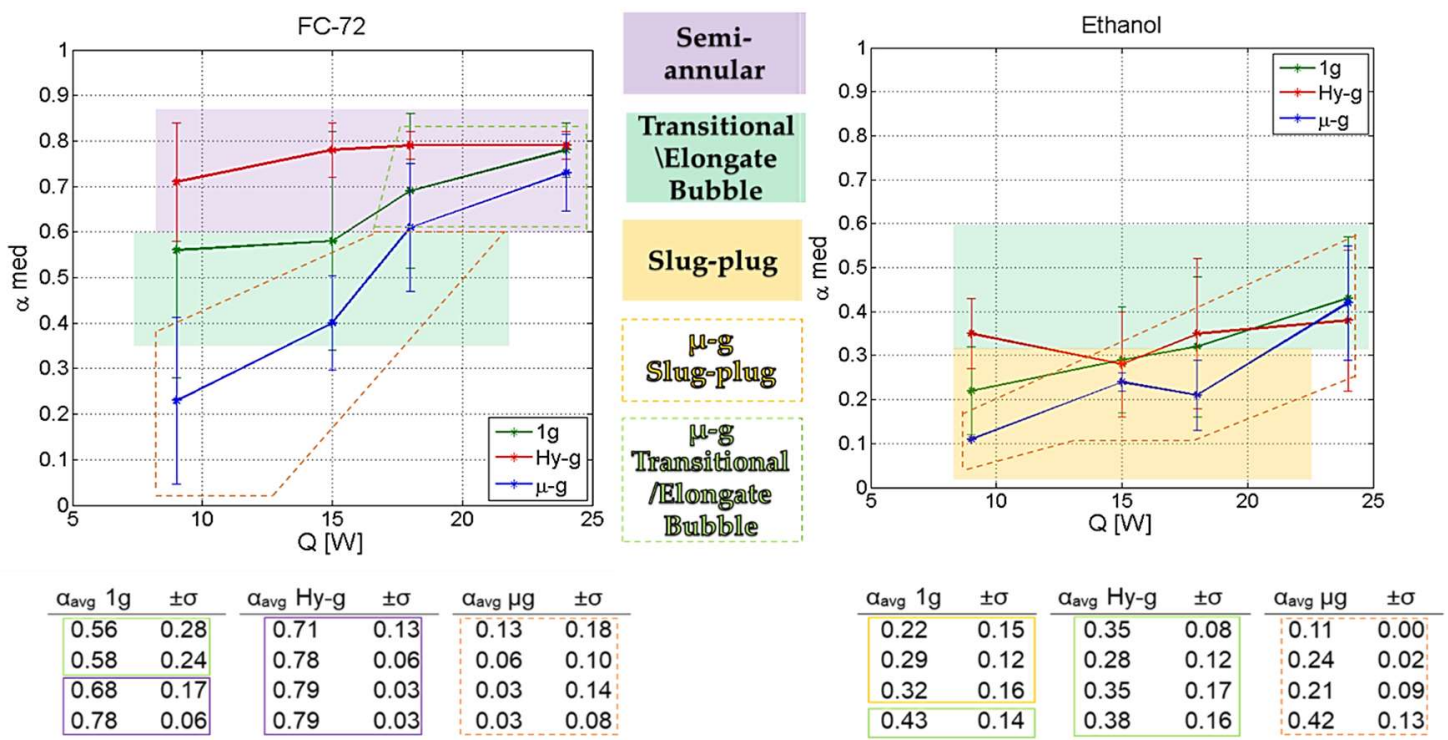

Figure 7 Comparison of evolution of average void fraction with standard deviation during parabolic flight for two working fluids.

Regarding the behaviour of the device as a Pulsating Heat Pipe, the dynamics of the fluid can be described as 
follow:

-During a phase of direct flow (from the condenser to the evaporator), a co-current liquid-vapour flow with slip ratio (ratio of the velocities of the gas and liquid phases) generally greater than 1, causes propagation of small disturbances from the advancing meniscus into the liquid film. Local thickening of the liquid film (ring waves) is observed with spatial distribution and radial extension linked to the amplitude and frequency of the initial disturbance with consequent non-uniform liquid entrapment between vapour bubble and wall. The frequency of the ridges tends to increase with the increase of the gravity field (1-g and Hyper-g level of a parabolic flight). This is in agreement with the experiments conducted on rising bubbles in unconfined media form [34];

-During a reverse flow phase (from the evaporator to the condenser), a short period of counter-current liquidvapour flow occurs, given the inertia of the liquid bulk, intense disturbances are generated causing the local thickening of the liquid film. This condition generally leads to the bubble break-up. A description of the behaviour of the same device supported by infrared imaging is available in Cattani et al. [37].

\subsection{The proposed flow pattern map}

To quantify the global flow conditions that determine the flow pattern in a thermally-induced accelerated twophase flow, the inertial effects on break-up mechanism have been considered, along with the length of the vapour bubble. The Weber (We), Froude (Fr) and Bond (Bo) numbers has been widely used to describe slug/plug flow dynamics giving satisfying results when used to describe break up mechanisms in the computational study conducted by Andredaki et al. [35]. In [35], the non-dimensional numbers have been formulated in a modified version $\left(\mathrm{We}_{l}{ }^{*}, \mathrm{Fr}_{l}{ }^{*}, \mathrm{Bo}_{l}{ }^{*}\right)$ considering: a) the velocity of the liquid $\left.v_{l} \mathrm{~b}\right)$ the acceleration of the liquid $(\mathrm{dv} / \mathrm{dt})$, resultant of all the external forces acting on the liquid slug including the gravitational field and pressure variation due to thermal effects [36], and c) the vapour bubble length $l_{b}$; to obtain a flow pattern map for the case of oscillating thermally-induced two-phase flow:

$$
B o_{l}^{* 0.5}=\left[\frac{\rho}{\sigma}\left(\frac{d v}{d t}\right)\right]^{0.5} D\left(\frac{l_{b}}{D}\right)
$$

expressing the ratio of external body forces to surface tension forces;

$$
F r_{l}^{*}=\frac{v}{\sqrt{\left(\frac{d v}{d t}\right) D\left(\frac{l_{b}}{D}\right)}}
$$

as a measure of the ratio between momentum forces and external body forces;

$$
W e_{l}^{*}=\frac{\rho v^{2} D}{\sigma} \cdot\left(\frac{l_{b}}{D}\right)
$$

Expressing the ratio between inertial and surface tension forces.

In equations (7), (8) and (9), the subscript 1 of the non-dimensional groups indicates they are considering the length of the vapour bubble as characteristic length; $D$ is the internal diameter of the channel. In order to better understand the contribution of the length of the bubble to the non-dimensional groups, the distribution of the ratio $l b / D$ in the analysed frames (expressed as the percentage of frames with $l b / D$ ratio over the total frame analysed) has been elaborated for the two fluids under four levels of power input and three gravity level conditions (Figure 10 ). For values of $l b / D>25$, the length of the bubble exceeds the dimension of the visualization channel, evolving to a condition of semi-annular flow. The role of the diameter is then intrinsically connected with the two different fluids, with the velocity field and the characteristic of the vapour phase (bubble length and void fraction distribution). The vapour phase characteristic length $(l b / D)$ is clearly affected by the power input, the gravity level and the working fluid. For ethanol, the increase in power input causes an evolution towards greater $l b / D$ values. Same evolution to higher characteristic lengths in case of increasing of the $g$ level. The two gravity levels shows velocity fields quite different: generally higher peaks and average for both velocities and acceleration in Hy-g as shown in Figure 9; considering that, and comparing Figure 10a and Figure 10b, the effect of inertia is to 
increase the length of the slug-plug bubbles. With FC-72, an increase in power at $1 \mathrm{~g}$ still causes a slight evolution towards greater $l b / D$ values, already characteristic of semi-annular flow, where the bubble completely fills the channel for $60-70 \%$ of the time or more. In Hy-g, a difference between power inputs is not appreciable and the semi-annular flow pattern evolves to a proper annular flow, present for $90 \%$ of the time or more. The microgravity phase triggers the transition to a confined condition, with slug-plug observable at all power level and generally much longer bubble compared to ethanol. The velocity of the microgravity phase slug-plug is practically zero for ethanol but can reaches peaks of 0.1-0.2 m/s in the case of the FC-72. The combined effect of inertia and fluid properties results in longer vapour bubbles for FC-72. Examples of the flow pattern observed under the different gravity levels, power inputs and working fluids are shown in Figure 8.

More than 1200 operating points of the PHP have been analysed and plotted on a novel map with $\mathrm{Fr}^{* 0.5} \mathrm{We}^{* 0.25}$ as ordinate and $\mathrm{Bo}^{* 0.5}$ as abscissa, in order to relate the effect of interface disturbance propagation and the ability of the surface tension to create and preserve bubbles, to the actual flow conditions (velocity and acceleration) on the confinement conditions.

As expected, the fluid in critical condition ( $D<d_{c r, B o}$, ethanol in Figure 11a) is mainly working in the slugplug regime. Transition to the annular regime occurs at the highest power input and in Hy-g, alternated with the slug-plug regime. The proposed maps are illustrated in Figure 12.

Two different zones of slug-plug flow are recognisable:

- The Micro-gravity Slug-Plug zone ( $\mu$-g conditions): which corresponds to the region approximately contained within the rectangle delimitated horizontally by $\mathrm{Fr}_{l}^{0.5} W e_{l}^{0.25}<1$ and vertically by $B o_{l}^{0.5}<1$. The proposed region is characterised by cases of non-activation of the device (no pressure oscillation detected and constant increase of the evaporator temperature) and therefore low velocities of the fluid as well as low accelerations (low inertial phenomena). The modified Bond number is the lowest registered among all cases analysed, influenced by the short length of the vapour plugs, as shown in Figure 10c. Surface tension is dominating over inertia and the length of the bubble falls within a range between $2 \mathrm{xD}$ and $6 \mathrm{xD}$ in most of the cases. Only at $24 \mathrm{~W}$, bubble length seems able to sporadically increase up to $21 \mathrm{xD}$ (Figure 10c). That can be explained with the sudden decrease of $\Delta \mathrm{P}$ at the ends of the bubble, allowing the bubble to expand, decreasing the vapour pressure of the bubble;

- The fully activated Slug-Plug: where the velocities involved are one order of magnitude higher than the micro-g cases. The range of modified Bo number goes up to 4 and the group $\mathrm{Fr}_{l}^{0.5} W e_{l}^{0.25}$ slightly decreases with $B o_{l}^{0.5}$ suggesting that surface tension forces are no longer prevailing with a great margin. High concentration of bubble coalescence events, that lead to a sensible increase in the bubble length, have been recorded along the line marking the upper limit of the operational points nebula. 
a)

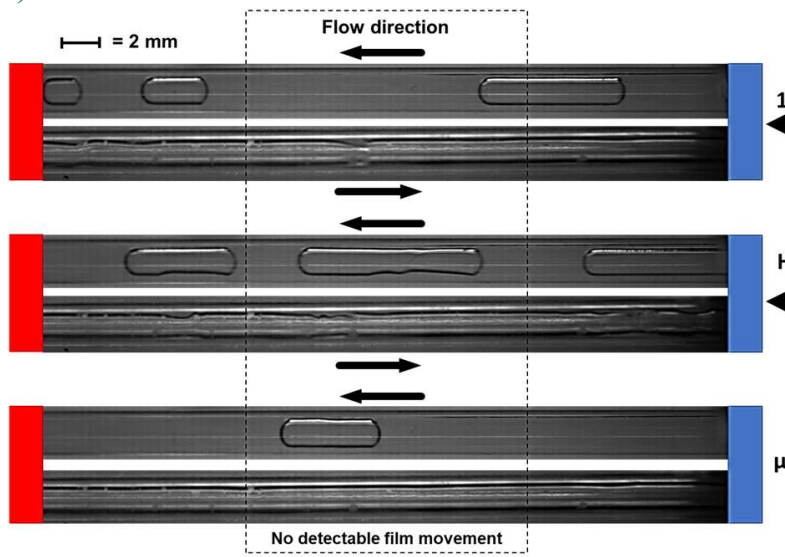

b)

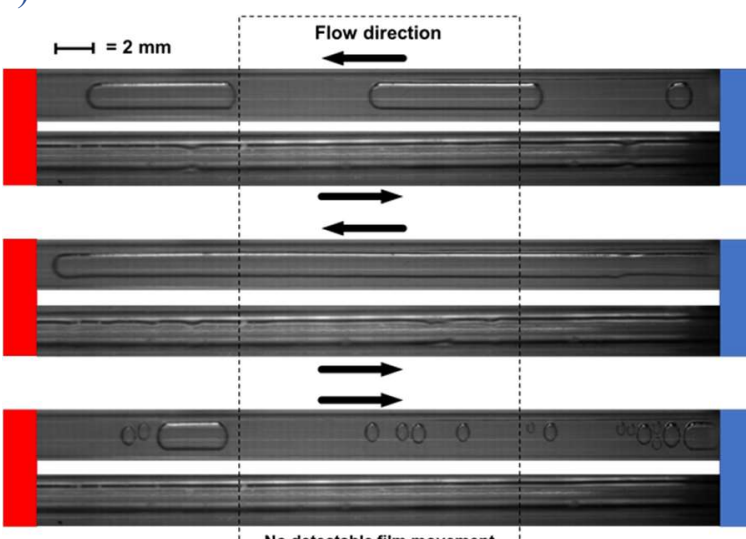

No detectable film movement

c)
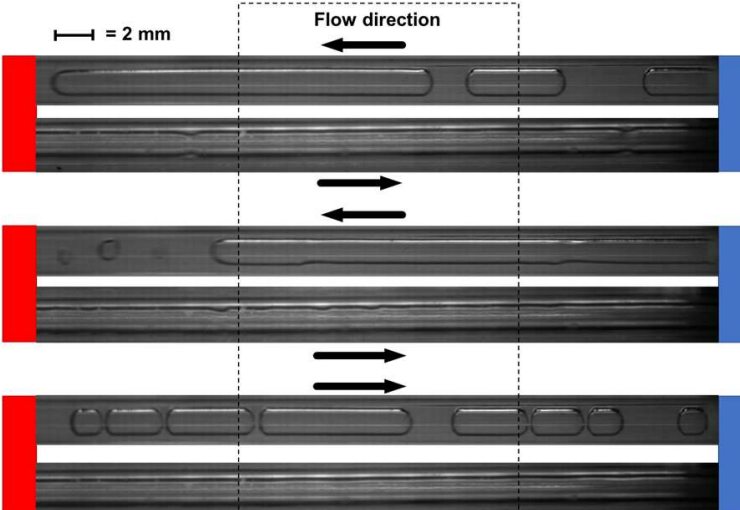

No detectable film movement d)

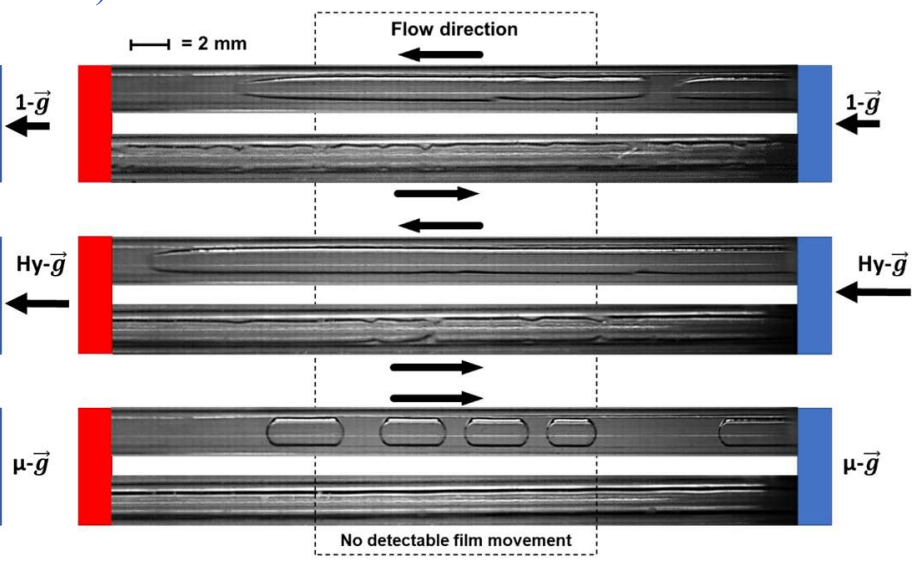

e)

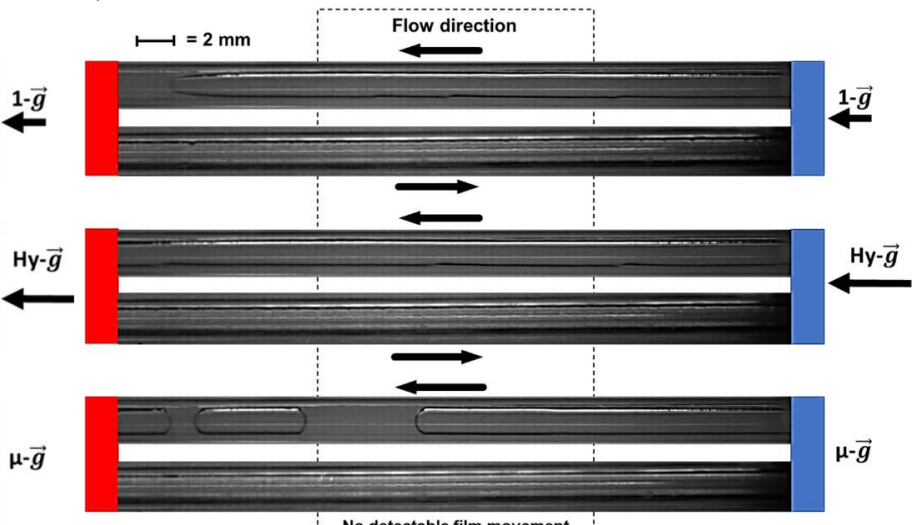

f)

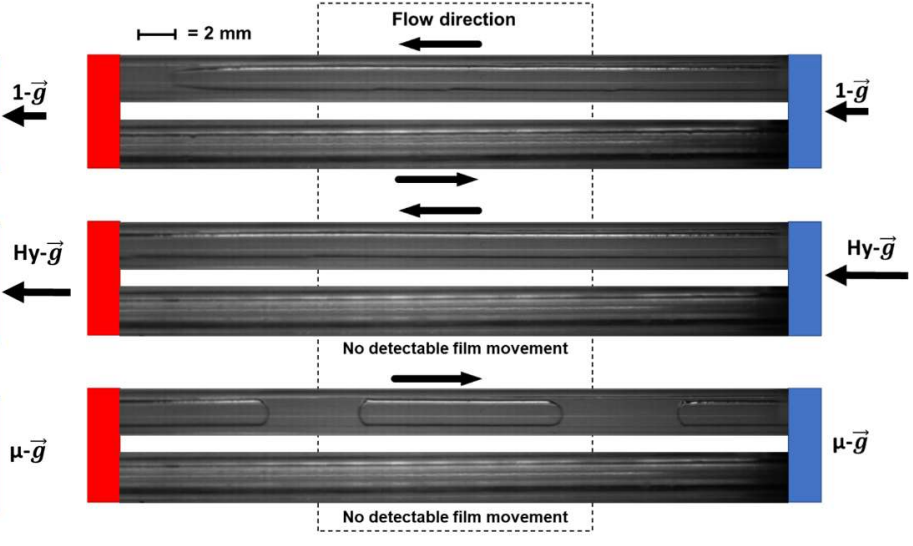

Figure 8 Typical flow pattern obtained with ethanol (left column) for low power input a) 9W, b) 18W, c) 24W. Typical flow pattern obtained with ethanol (right column) for low power input d) $9 \mathrm{~W}$, e) $18 \mathrm{~W}$, f) $24 \mathrm{~W}$. Evaporator side in red, condenser side in blue. 
a)

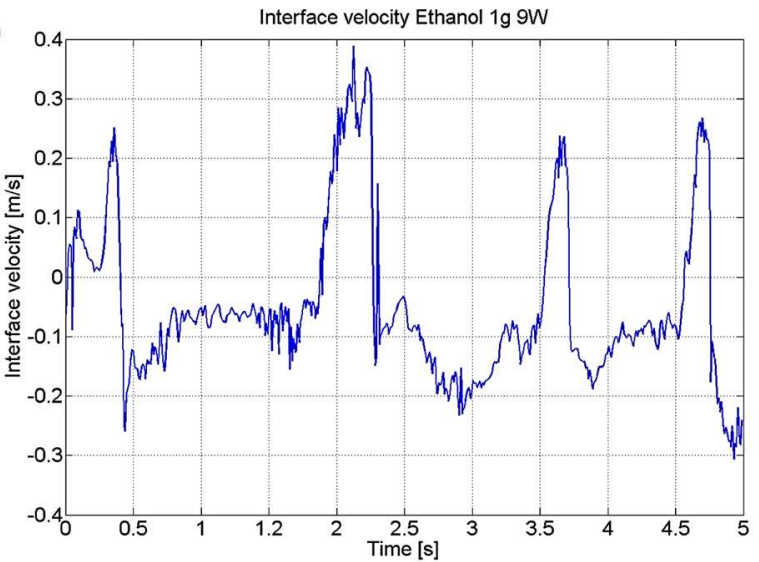

c)

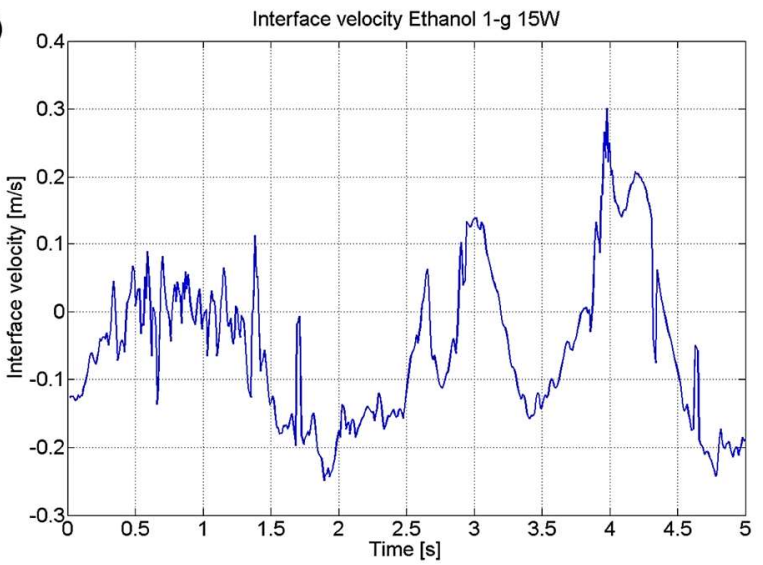

e)

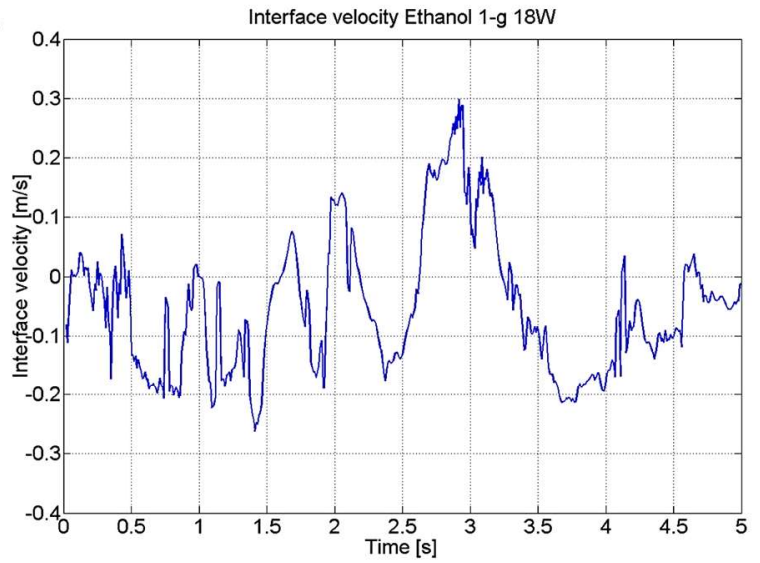

g)

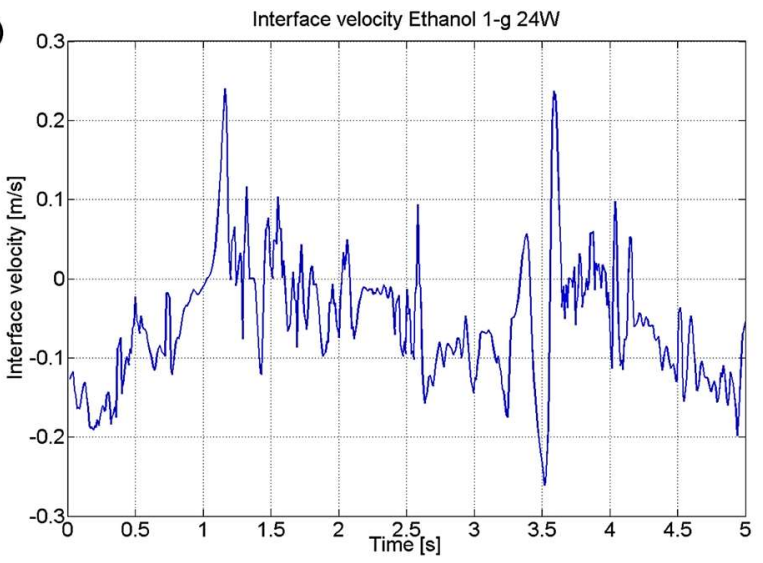

b)

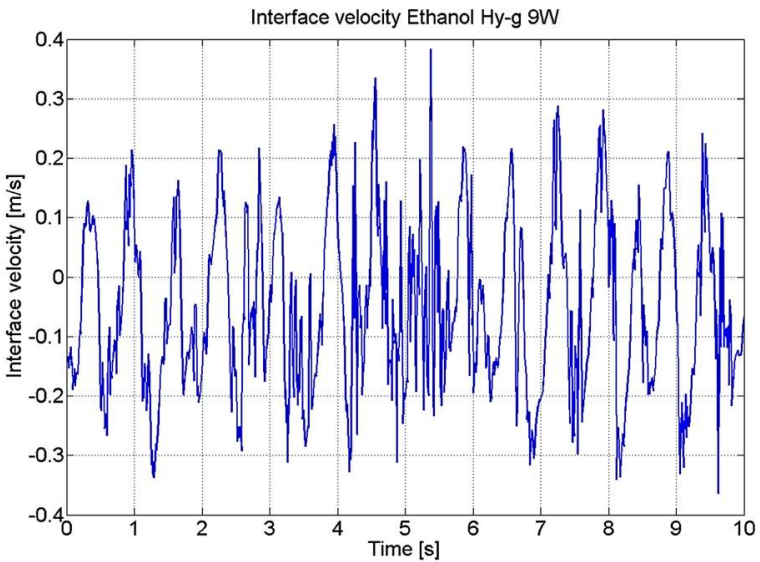

d)

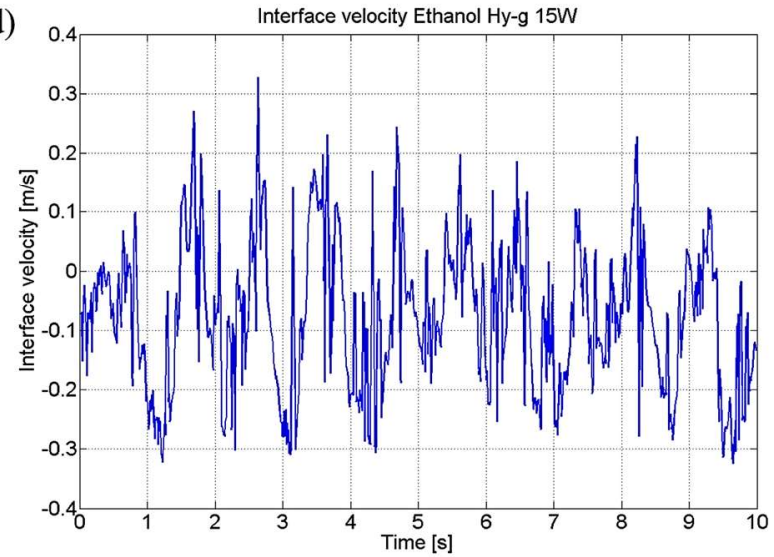

f)

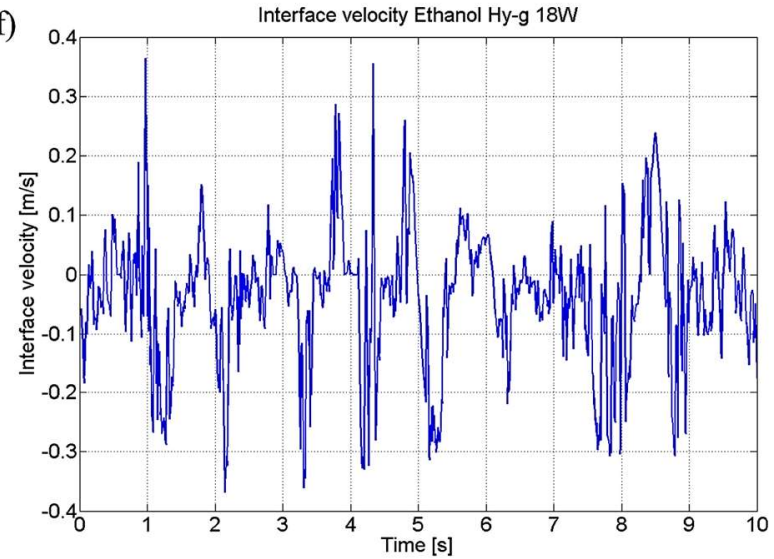

h)

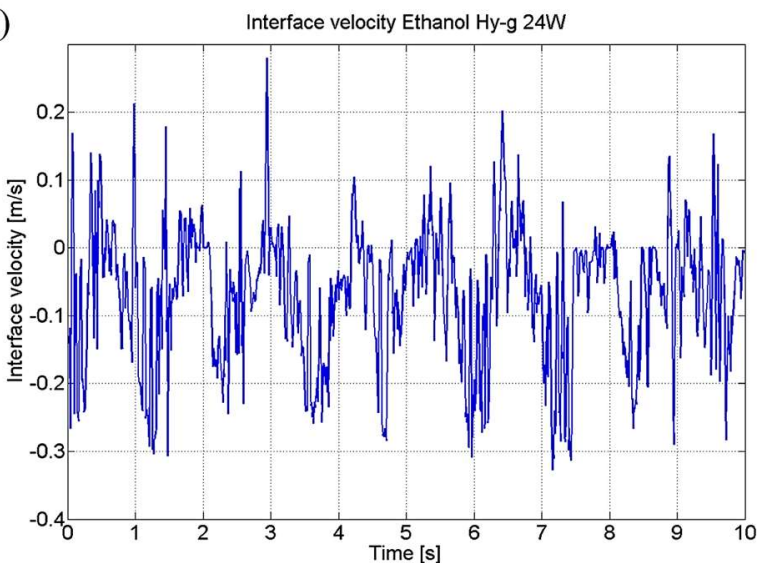

Figure 9 Interface velocity obtained for Ethanol under 1-g at: a) $9 \mathrm{~W}$ c) $15 \mathrm{~W}$ e) $18 \mathrm{~W}$ and g) $24 \mathrm{~W}$. Interface velocity for ethanol under Hy-g at: b) $9 \mathrm{~W}$ d) $15 \mathrm{~W}$ f) $18 \mathrm{~W}$ and h) $24 \mathrm{~W}$. 
a)

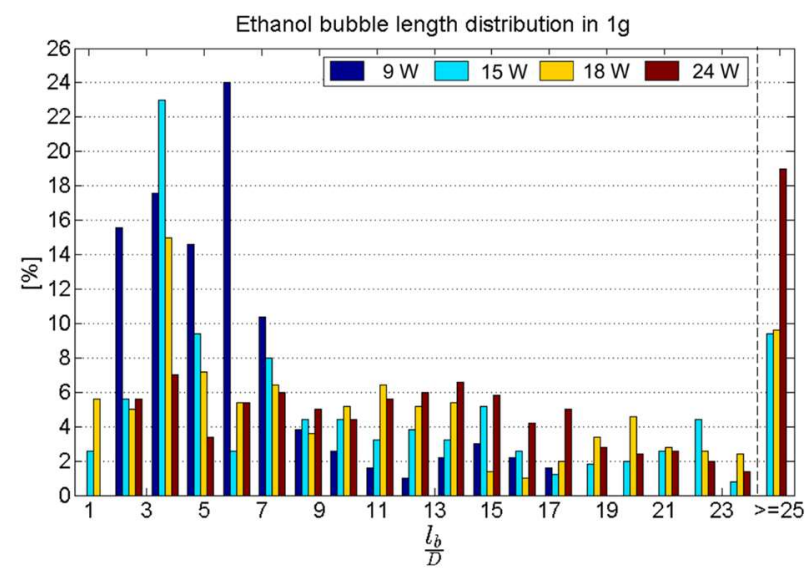

b)

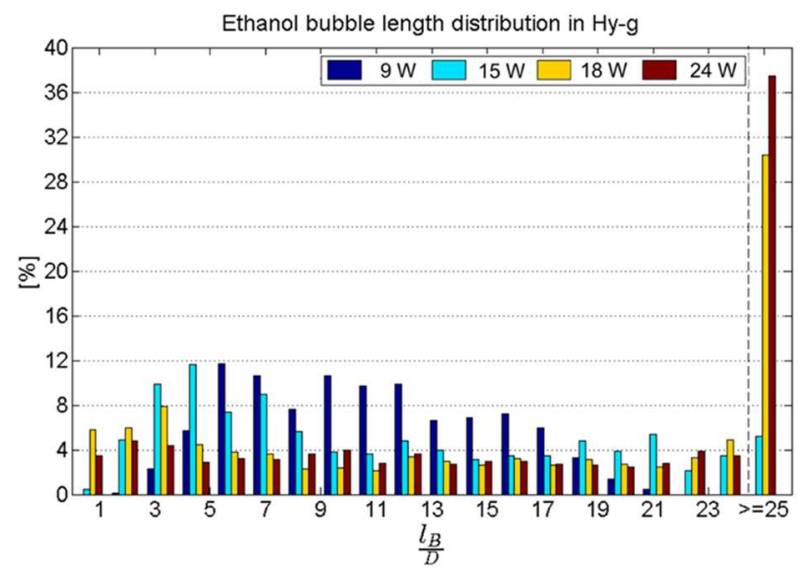

c)

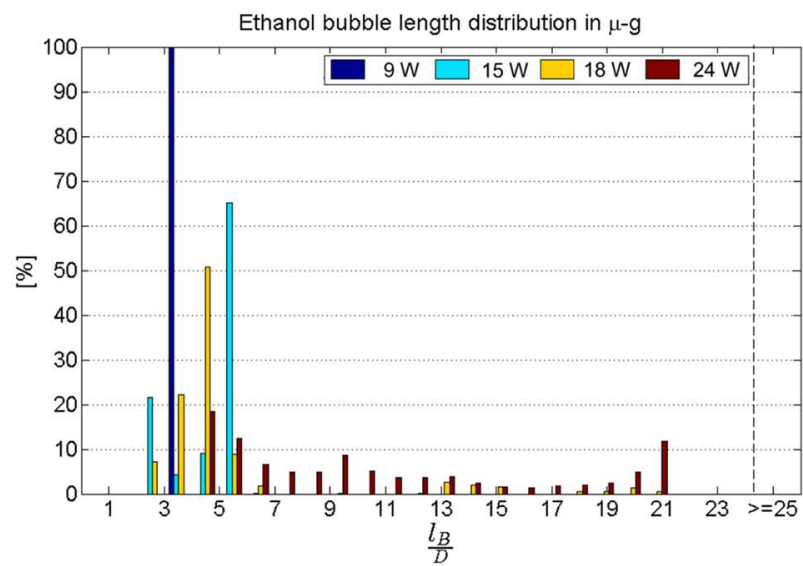

d)

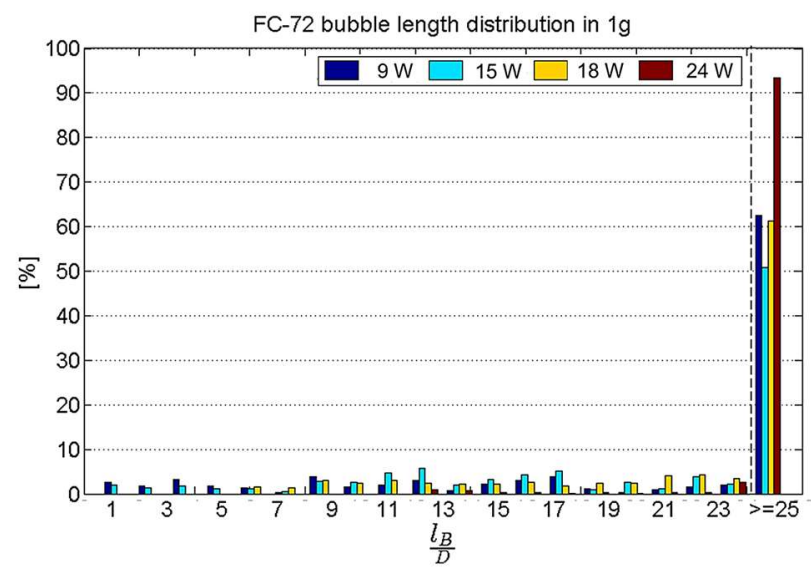

e)

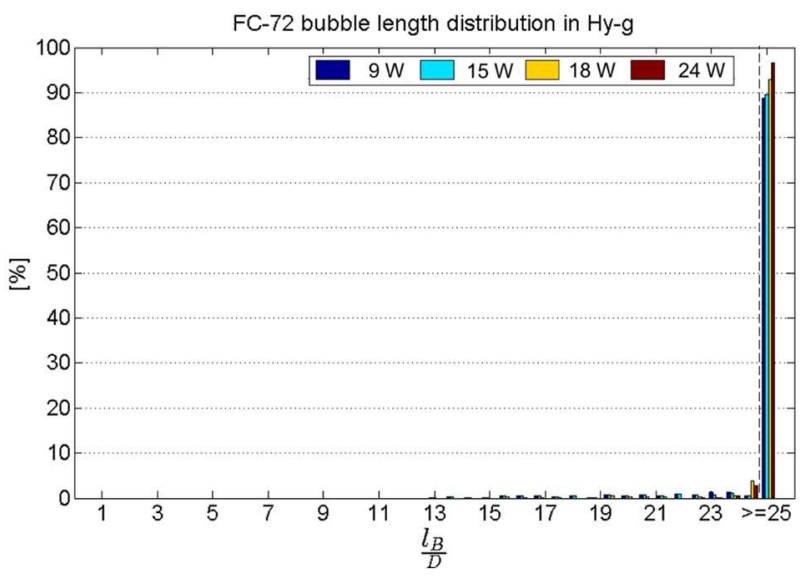

f)

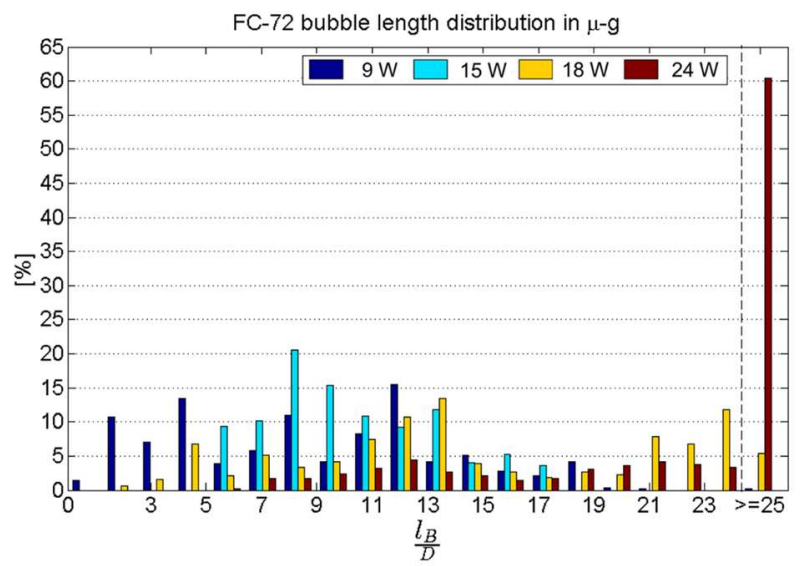

Figure 10 Distribution of the $l_{b} / D$ ratio in the analysed frames, varying power input and gravity level: a) Ethanol $1 \mathrm{~g}, \mathrm{~b}$ ) Ethanol Hy-g, c) Ethanol $\mu$-g, d) FC-72 1g, e) FC-72 Hy-g, e) FC-72 $\mu$-g. The ordinate indicates the percentage of frames that show a specific $l_{b} / D$ ratio.

Annular operational points, magenta square markers in Figure 12, occupy the right-hand side of the nebula. Long bubble length is expected from Hy-g and 1-g high power input conditions. The slug-plug flow, in facts, tends to increase its length with the power input at $1-\mathrm{g}$ and Hy-g gravity levels. Perturbations can travel more along a bubble, facilitated by a high slip ratio between the two phases and sudden peaks of acceleration during inversion 
phases, typical of the oscillatinglpulsating motion. An anomaly in the distribution of break-up events has been noticed along the line that marks the right limit of the annular operational points nebula. The slope of the right boundary line defines a decrease of the modified Bond number with a reduction of the velocity of the flow or a reduction of the bubble length. A zone where slug-plug and annular flow points overlap is clearly present in the map. This constitutes a zone of transitional flow called transition zone.

a)

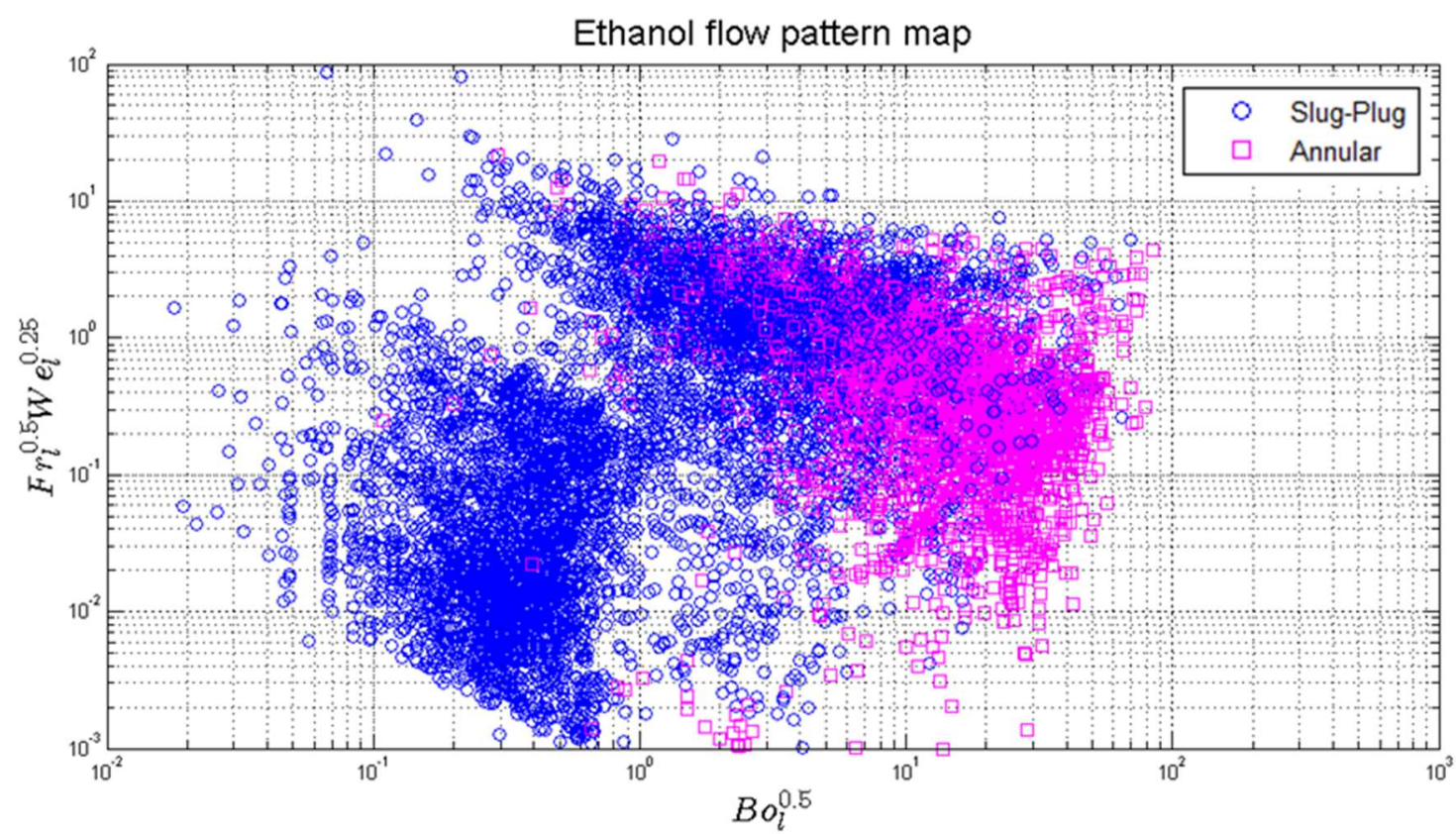

b)

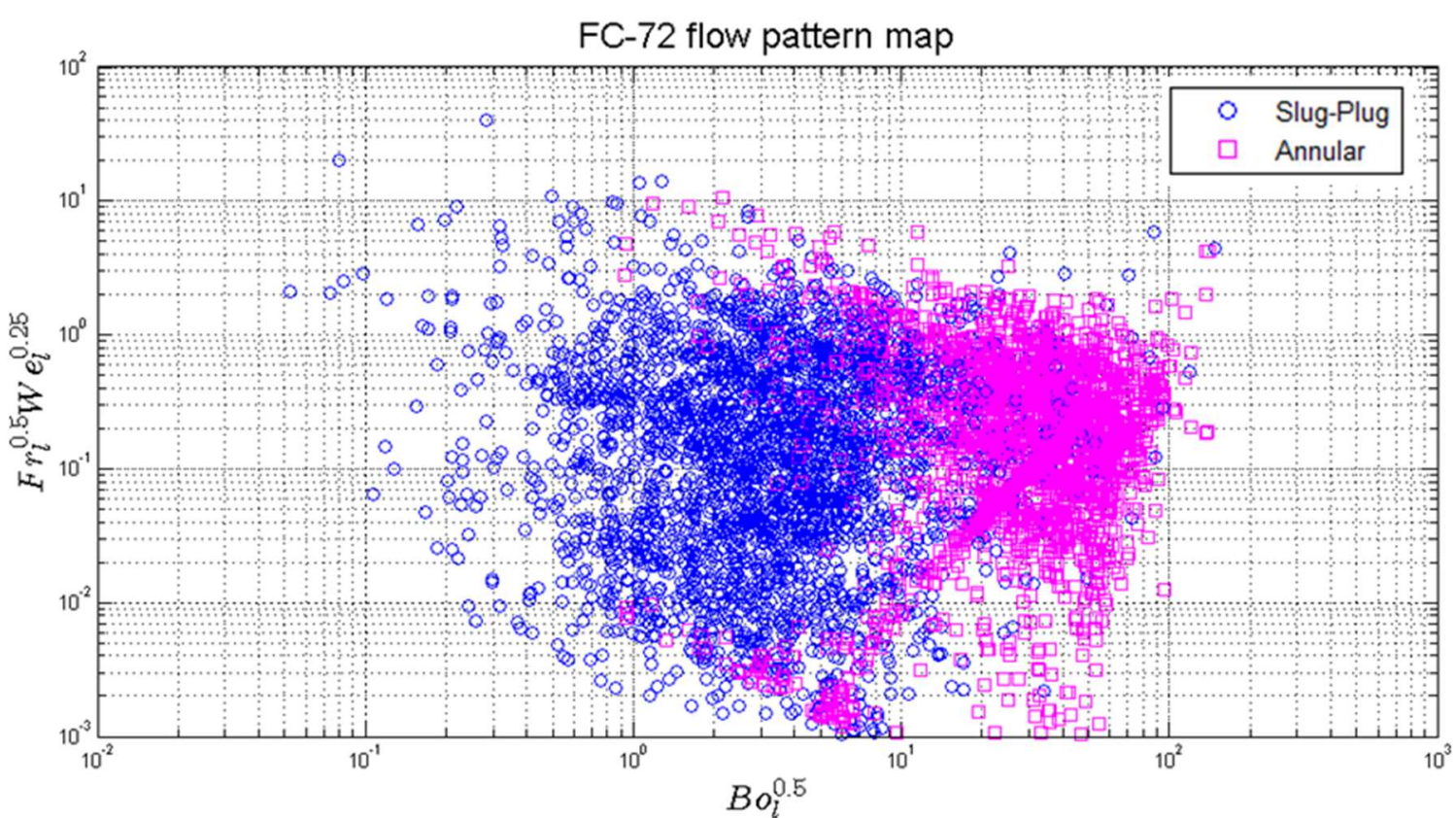

Figure 11 Flow pattern map in terms of dynamic non-dimensional groups with bubble length as characteristic length; adiabatic section of a single loop PHP. a) Ethanol b) FC-72.

8 Overlapping the two operational maps, a generalised map independent from the working fluid can be obtained 9 (Figure 12). This map shows a general accordance on the flow pattern transition boundaries and operational limits given by the break up and coalescence events. 


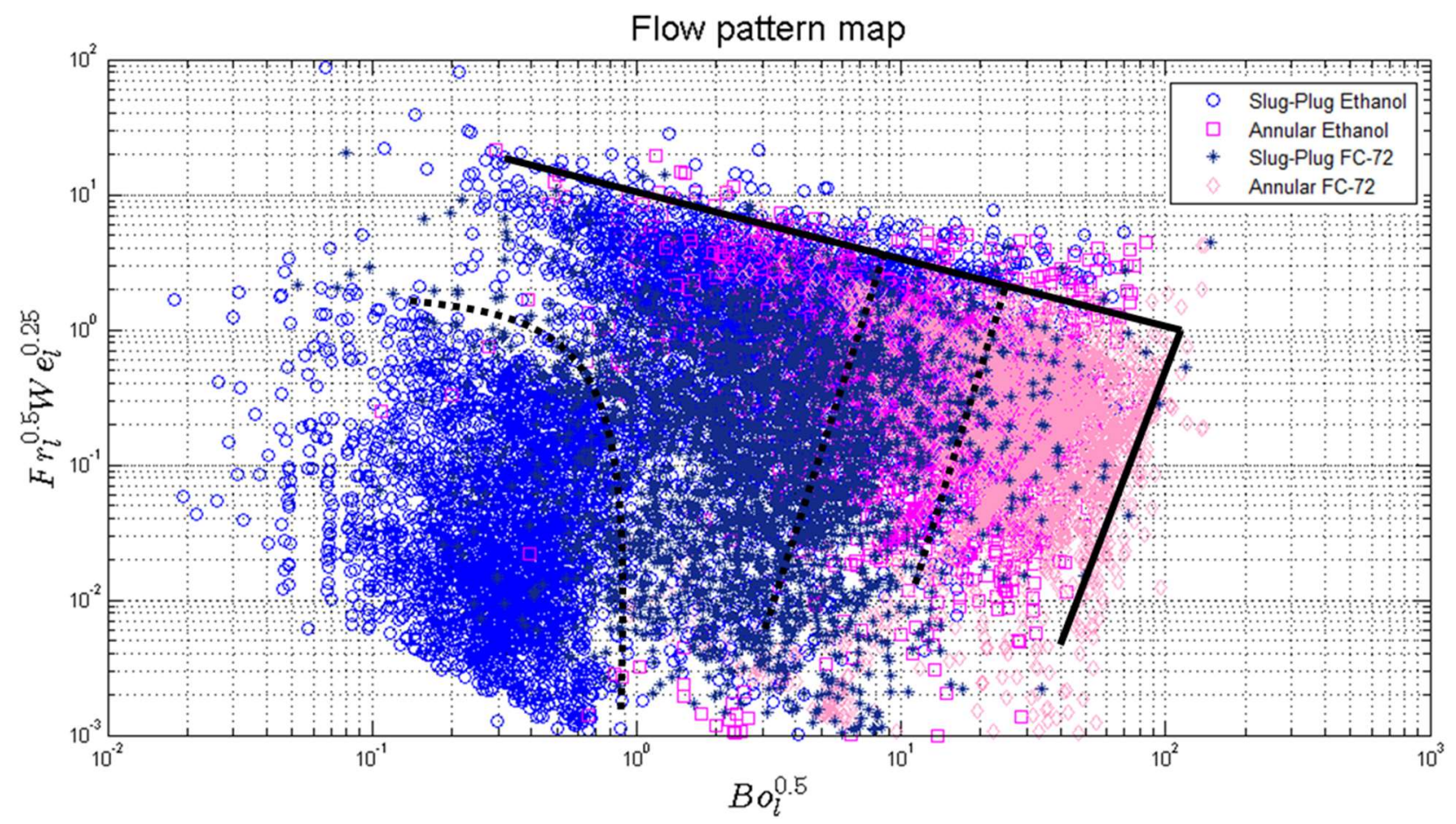

Figure 12 Flow pattern map for Ethanol and FC-72 in terms of dynamic non-dimensional groups with bubble length as characteristic length; adiabatic section of a single loop PHP.

A general operational map able to predict the flow pattern and the bubble break-up of a two-phase flow in a thermally driven PHP-like device, is proposed in Figure 13. The applicable ranges for the map are listed in Table 4. This novel theory considers velocity, actual acceleration of the fluid and the length of the bubble having active role in defining the evolution of the fluid flow towards a slug-plug condition or a annular condition and in predicting break-up events. The new flow pattern transition correlations, obtained by means of curve fitting based on qualitative transition limits are reported below:

Slug-plug dominant to transitional regime:

$$
\mathrm{Fr}^{* 0.25} \mathrm{~W} e^{* 0.25}=0.0059\left(B o^{* 0.5}\right)^{2.45}
$$

Transitional regime to annular dominant:

$$
\mathrm{Fr}^{* 0.25} \mathrm{~W} e^{* 0.25}=0.0009\left(B o^{* 0.5}\right)^{2.02}
$$

Upper limit (Coalescence):

$$
\mathrm{Fr}^{* 0.25} W e^{* 0.25}=12.42\left(B o^{* 0.5}\right)^{-0.69}
$$

Right limit (Break-up):

$$
\mathrm{Fr}^{* 0.25} \mathrm{~W} \mathrm{e}^{* 0.25}=6 * 10^{-7}\left(\mathrm{Bo}^{* 0.5}\right)^{2.94}
$$

Whilst for the upper and right limits the curve fitting process is helped by the sharp absence of experimental points outside of the nebula, the limits between dominant flow pattern have been identified with a curve fitting affected by a certain grade of subjectivity. For this reason, solid lines and dashed lines have been used in Figure 13.

To notice, even if the effect of the fluid viscosity is very important, due to the small number of fluids considered in the present work, the Reynolds number, or the Ohnesorge number or the Capillary number have not yet been taken into account in the correlations. 
Table 4 Applicable ranges for the proposed map

\begin{tabular}{|c|c|c|}
\hline Fluid property & Min & Max \\
\hline Density & $740 \mathrm{Kg} / \mathrm{m} 3$ & $1700 \mathrm{Kg} / \mathrm{m} 3$ \\
\hline Surface Tension & $0.005 \mathrm{~N} / \mathrm{m}$ & $0.025 \mathrm{~N} / \mathrm{m}$ \\
\hline Liquid viscosity & \multicolumn{2}{|c|}{ Not considered } \\
\hline Flow characteristic & \multicolumn{2}{|}{} \\
\hline Velocity (absolute value) & $0.004 \mathrm{~m} / \mathrm{s}$ & $0.6 \mathrm{~m} / \mathrm{s}$ \\
\hline Acceleration (absolute value) & $0.05 \mathrm{~g}$ & $20 \mathrm{~g}$ \\
\hline Thermodynamic parameter & \multicolumn{2}{|}{} \\
\hline Temperature & $293 \mathrm{~K}$ & $315 \mathrm{~K}$ \\
\hline Heat Flux & $6.5 \mathrm{~W} / \mathrm{cm} 2$ & $13.6 \mathrm{~W} / \mathrm{cm} 2$ \\
\hline
\end{tabular}

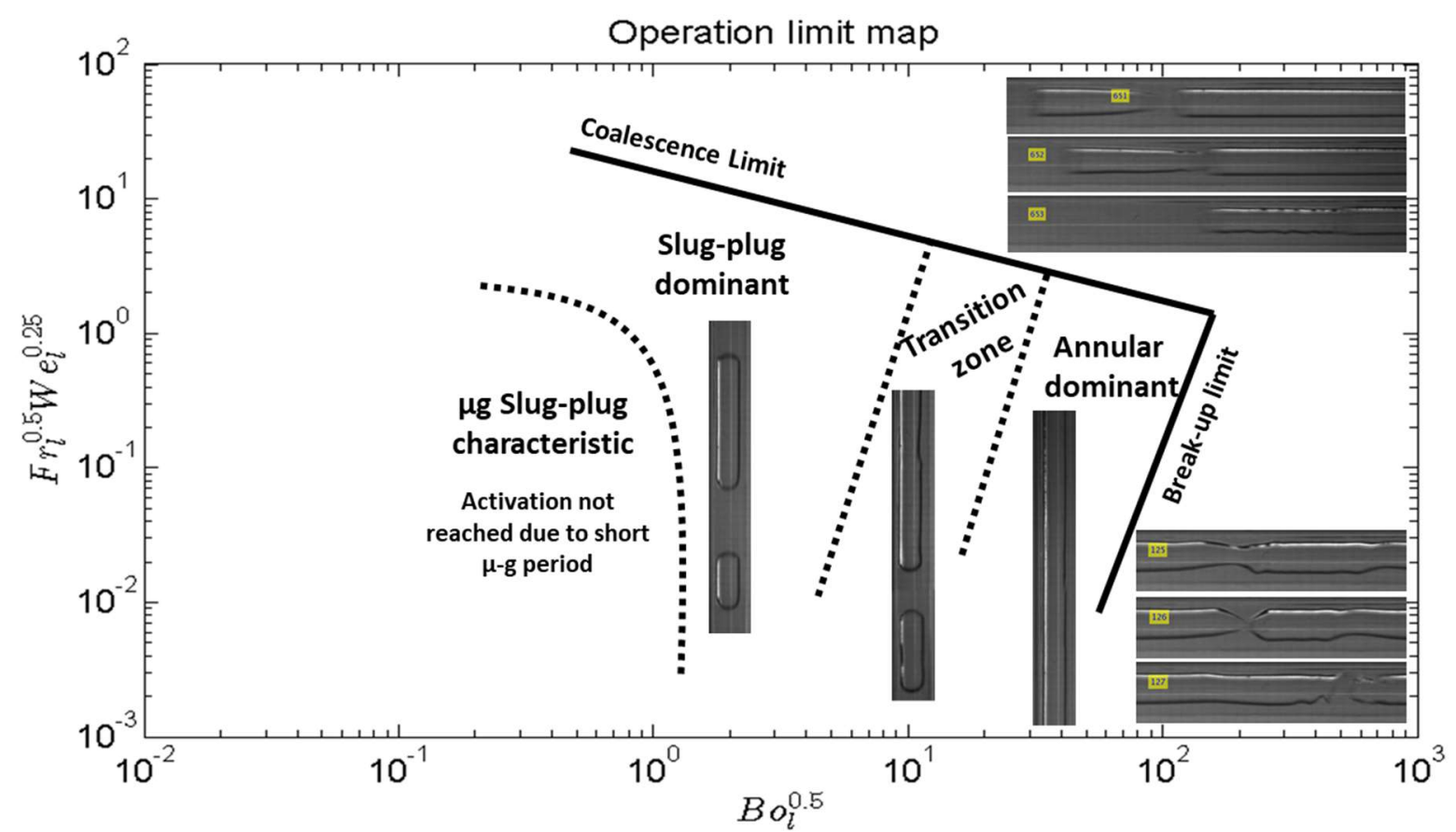

Figure 13 Flow pattern map of an accelerated slug-plug flow independent from the working fluid and for a given liquid viscosity, obtained under three different gravity levels and varying power input.

\section{CONCLUSIONS}

The aim of this investigation is to observe and characterise the flow regime transitions in a millimetric channel when the mass flow rate is not controlled neither constant, but results from thermally induced phenomena like evaporation/condensation. An experimental investigation of an accelerated and oscillating two-phase fluid flow in a single loop passive heat transfer device has been carried out, providing with high-speed imaging from which a dynamic qualitative characterization of the flow has been made. The inertial effect on flow pattern transitions have been reviewed and discussed; the fluid acceleration and velocity have been identified having a determinant role on the confinement conditions, confirming that only a static confinement criterion cannot fully represent an oscillating flow over a range of operating conditions. The vapour phase characteristic length has been investigated and is clearly affected by the power input and the varying gravity level besides the working fluid. A new flow pattern map with modified Bond, Weber and Froude numbers accounting including the parameters that were not considered yet in the literature such as the actual acceleration of the fluid rather than a constant value of $g$ and the length of the bubbles as characteristic length, has been proposed. The distribution of more than 1200 operating points on the new system of coordinates, marks the transitions from surface tension dominated slug/plug flow to 
shear dominated annular flow, based on comparison with high-speed imaging. The proposed flow pattern transition map is independent from the working fluid and the gravity level and shows also neat borders associated with the coalescence limit and break-up limits. Those limits can be implemented, for instance, in lumped numerical codes for the simulation of Pulsating Heat Pipes or in VOF-CFD models, to eliminate the a priori assumptions on the existence of a slug-plug flow pattern. Future works will aim at increasing the applicable ranges for the proposed map testing different ranges of temperature and diameters and taking into account the fluid viscosity.

\section{ACKNOWLEDGEMENTS}

The present work has been carried out in the frameworks of the ESA MAP INWIP and the EPSRC UK HyHP (EP/P013112/1) research projects. The Authors would like to thank the NOVESPACE and ESA team in Bordeaux for their on-ground and in-flight technical support, particularly Ms. Jaquemet and Mr. Melville. Special thanks to Dr. Balazs Toth for his constant interest and support. Thanks also to Mr. Sykes (School of Computing, Engineering and Mathematics, University of Brighton), Mr. Palermo and Mr. Stevens (Advanced Engineering Centre, University of Brighton).

\section{NOMENCLATURE}

$16 \quad a \quad:$ Interface acceleration $\left[\mathrm{m} / \mathrm{s}^{2}\right]$

17 Bo : Bond number [-]

18 D : Diameter [m]

19 Co : Confinement number [-]

$20 \mathrm{Fr} \quad$ : Froude number [-]

$21 \quad g \quad$ : gravitational field acceleration $\left[\mathrm{m} / \mathrm{s}^{2}\right]$

$22 \quad G a$ : Garimella number [-]

$23 \quad l$ : Length [m]

$24 v \quad:$ Interface velocity $[\mathrm{m} / \mathrm{s}]$

25 We : Weber number [-]

$27 \quad \alpha \quad$ : Void fraction [-]

$28 \quad \delta \quad$ : Liquid film thickness [m]

$29 \mu$ : Dynamic viscosity [Pa s]

$30 \quad \rho \quad:$ Density $\left[\mathrm{kg} / \mathrm{m}^{3}\right]$

$31 \quad \sigma \quad$ : Surface tension $[\mathrm{N} / \mathrm{m}]$

\section{Subscripts}

$34 \quad b \quad$ : Bubble

$35 \quad c$ : Condenser

36 crit : Critical conditions

$37 e$ : Evaporator

\section{REFERENCES}

[1]L. Cheng, G. Ribatski, and J. R. Thome, 'Two-Phase Flow Patterns and Flow-Pattern Maps : Fundamentals and applications', Appl. Mech. Rev., vol. 61, 2008.

[2]S. K. Saha and G. P. Celata, Instability in Flow Boiling in Microchannels, Springer. 2016.

[3]P. Cheng and H. Y. Wu, 'Mesoscale and Microscale Phase-Change Heat Transfer', Adv. Heat Transf., 
vol. 39, pp. 461-463, 2006.

[4]P. A. Kew and K. Cornwell, 'Correlations for the prediction of boiling heat transfer in small-diameter channels', Appl. Therm. Eng., vol. 17, no. 8-10, pp. 705-715, 1997.

[5]T. Harirchian and S. V. Garimella, 'A comprehensive flow regime map for microchannel flow boiling with quantitative transition criteria', Int. J. Heat Mass Transf., vol. 53, no. 13-14, pp. 2694-2702, 2010.

[6]C. Baldassari and M. Marengo, 'Flow boiling in microchannels and microgravity', Prog. Energy Combust. Sci., vol. 39, no. 1, pp. 1-36, 2013.

[7]N. Shao, A. Gavriilidis, and P. Angeli, 'Flow regimes for adiabatic gas-liquid flow in microchannels', Chem. Eng. Sci., vol. 64, no. 11, pp. 2749-2761, 2009.

[8]J. R. Thome, A. Bar-Cohen, R. Revellin, and I. Zun, 'Unified mechanistic multiscale mapping of two-phase flow patterns in microchannels', Exp. Therm. Fluid Sci., vol. 44, pp. 1-22, 2013.

[9]M. Marengo and V. Nikolayev, 'Pulsating heat pipes: experimental analysis, design and applications Marco', in Encyclopedia of Two-Phase Heat Transfer and Flow IV, vol. 1, J. R. Thome, Ed. World Scientific, 2018.

[10]K. Smith, R. Kempers, and A. J. Robinson, 'Confinement and vapour production rate influences in closed two-phase reflux thermosyphons Part A: Flow regimes', Int. J. Heat Mass Transf., vol. 119, pp. 907-921, 2018.

[11]K. Smith, A. J. Robinson, and R. Kempers, 'Confinement and vapour production rate influences in closed two-phase reflux thermosyphons Part B : Heat transfer', Int. J. Heat Mass Transf., vol. 120, pp. 1241-1254, 2018.

[12]M. Manzoni, M. Mameli, C. de Falco, L. Araneo, S. Filippeschi, and M. Marengo, 'Advanced numerical method for a thermally induced slug flow: Application to a capillary closed loop pulsating heat pipe', Int. J. Numer. Methods Fluids, vol. 82, no. 7, pp. 375-397, 2016.

[13]V. S. Nikolayev, 'A Dynamic Film Model of the Pulsating Heat Pipe', J. Heat Transfer, vol. 133, no. 8, p. $081504,2011$.

[14]J. Bae, S. Y. Lee, and S. J. Kim, 'Numerical investigation of effect of film dynamics on fluid motion and thermal performance in pulsating heat pipes', Energy Convers. Manag., vol. 151, no. August, pp. 296310, 2017.

[15]R. Revellin and J. R. Thome, 'A new type of diabatic flow pattern map for boiling heat transfer in microchannels', J. Micromechanics Microengineering, vol. 17, no. 4, pp. 788-796, 2007.

[16]C. L. Ong and J. R. Thome, 'Macro-to-microchannel transition in two-phase flow: Part 1 - Twophase flow patterns and film thickness measurements', Exp. Therm. Fluid Sci., vol. 35, no. 1, pp. 37-47, 2011.

[17]G. P. Celata, M. Cumo, D. Dossevi, R. T. M. Jilisen, S. K. Saha, and G. Zummo, 'Flow pattern analysis of flow boiling inside a $0.48 \mathrm{~mm}$ microtube', Int. J. Therm. Sci., vol. 58, pp. 1-8, 2012.

[18]G. Puccetti, M. Tosi, B. Pulvirenti, and G. L. Morini, 'Flow patterns of an air - water mixture at the exit of a micro T-junction', Exp. Therm. Fluid Sci., vol. 67, pp. 62-69, 2015.

[19]S. Saisorn and S. Wongwises, 'Adiabatic two-phase gas-liquid flow behaviors during upward flow in a vertical circular micro-channel', Exp. Therm. Fluid Sci., vol. 69, pp. 158-168, 2015.

[20]S. Malhotra and S. Ghosh, 'Effects of channel diameter on flow pattern and pressure drop for airwater flow in serpentine gas channels of PEM fuel cell-An Ex situ experiment', Exp. Therm. Fluid Sci., vol. 100, no. September 2018, pp. 233-250, 2019.

[21]R. Gupta, D. F. Fletcher, and B. S. Haynes, 'Taylor Flow in Microchannels: A Review of Experimental and Computational Work', J. Comput. Multiph. Flows, vol. 2, no. 1, pp. 1-31, 2010.

[22]V. Ayel, L. Araneo, P. Marzorati, C. Romestant, Y. Bertin, and M. Marengo, 'Visualization of Flow Patterns in Closed Loop Flat Plate Pulsating Heat Pipe Acting as Hybrid Thermosyphons under Various 
Gravity Levels', Heat Transf. Eng., 2018.

[23]S. Z. Rouhani and M. S. Sohal, 'Two-phase flow patterns: A review of research results', Prog. Nucl. Energy, vol. 11, no. 3, pp. 219-259, 1983.

[24]K. Muramatsu, Y. Youn, Y. Han, Y. Hasegawa, and N. Shikazono, 'Numerical study on the effect of initial flow velocity on liquid film thickness of accelerated slug flow in a micro tube', Int. J. Heat Fluid Flow, vol. 54, pp. 77-86, 2015.

[25]Y. J. Youn, Y. Han, and N. Shikazono, 'Liquid film thicknesses of oscillating slug flows in a capillary tube', Int. J. Heat Mass Transf., vol. 124, pp. 543-551, 2018.

[26]H. Ide, R. Kuroshima, and M. Kawaji, 'Investigation of Ring Waves in Gas-Liquid Two-Phase Flow in a Microchannel', Heat Transf. Eng., vol. 37, no. 11, pp. 912-920, 2016.

[27]X. Wang, C. Zhu, T. Fu, T. Qiu, and Y. Ma, 'Critical condition for bubble breakup in a microfluidic flow-focusing junction', Chem. Eng. Sci., vol. 164, pp. 178-187, 2017.

[28]L. Pietrasanta, D. Mangini, D. Fioriti, N. Miche, M. Andredaki, A. Georgoulas, L. Araneo, and M. Marengo, 'A Single Loop Pulsating Heat Pipe in varying gravity conditions: experimental results and numerical simulations', p. 23891, 2018.

[29]V. Pletser, 'European aircraft parabolic flights for microgravity research, applications and exploration: A review', Reach - Rev. Hum. Sp. Explor., vol. 1, pp. 11-19, 2016.

[30]D. Mangini, M. Marengo, L. Araneo, M. Mameli, D. Fioriti, and S. Filippeschi, 'Infrared analysis of the two phase flow in a single closed loop pulsating heat pipe', Exp. Therm. Fluid Sci., vol. 97, no. September 2017, pp. 304-312, 2018.

[31]L. Pietrasanta, D. Mangini, D. Fioriti, N. Miche, A. Georgoulas, M. Andredaki, L. Araneo, and M. Marengo, 'A single loop pulsating heat pipe in varying gravity conditions: experimental results and numerical simulations', in 16th International Heat Transfer Conference, IHTC-16, Beijing, China, 10-15 August, 2018, 2018.

[32]Z. J. Taylor, R. Gurka, G. A. Kopp, and A. Liberzon, 'Long-Duration Time-Resolved PIV to Study Unsteady Aerodynamics', IEEE Trans. Instrum. Meas., vol. 59, no. 12, pp. 3262-3269, 2010.

[33]G. Spinato, N. Borhani, and J. R. Thome, 'Understanding the self-sustained oscillating two-phase flow motion in a closed loop pulsating heat pipe', Energy, vol. 90, pp. 889-899, 2015.

[34]G. K. Batchelor, 'The stability of a large gas bubble rising through liquid', J. Fluid Mech., vol. 184, pp. 399-422, 1987.

[35]M. Andredaki, A. Georgoulas, D. Mangini, L. Araneo, L. Pietrasanta, N. Miche, and M. Marengo, 'Computational study on break-up mechanisms of isolated vapour slugs during saturated flow boiling conditions', in 16th International Heat Transfer Conference, IHTC-16, Beijing, China, 10-15 August, 2018, 2018.

[36]K. Moriyama and A. Inoue, 'Thickness of the liquid film formed by a growing bubble in a narrow gap between two horizontal plates', J. Heat Transf., vol. 118, pp. 132-139, 1996.

[37]L. Cattani, D. Mangini, F. Bozzoli, L. Pietrasanta, N. Miche, M. Mameli, S. Filippeschi, S. Rainieri, and M. Marengo, 'An original look into pulsating heat pipes: Inverse heat conduction approach for assessing the thermal behaviour', Therm. Sci. Eng. Prog., vol. 10, no. February, pp. 317-326, 2019. 